\title{
Structure-Activity Relationship Studies of Pyridine-Based Ligands and Identification of a Fluorinated Derivative for the Positron Emission Tomography Imaging of Cannabinoid Type 2 Receptors
}

\author{
Ahmed Haider ${ }^{\dagger 1}$, Julian Kretz ${ }^{\dagger 2}$, Luca Gobbi ${ }^{2}$, Hazem Ahmed ${ }^{1}$, Kenneth Atz ${ }^{2}$, Markus Bürkler ${ }^{2}$, Christian Bartelmus ${ }^{2}$, Jürgen Fingerle ${ }^{2}$, Wolfgang Guba ${ }^{2}$, \\ Christoph Ullmer ${ }^{2}$ Michael Honer ${ }^{2}$, Irene Knuesel ${ }^{2}$, Markus Weber ${ }^{3}$, Andreas Brink ${ }^{2}$, Adrienne Müller Herde ${ }^{1}$, Claudia Keller ${ }^{1}$, Roger Schibli ${ }^{1,4}$, Linjing Mu ${ }^{1,4}$, \\ Uwe Grether $^{2}$, Simon M. Ametamey ${ }^{1}$ \\ ${ }^{1}$ Institute of Pharmaceutical Sciences, ETH Zurich, Vladimir-Prelog-Weg 4, CH-8093 Zurich, Switzerland \\ ${ }^{2}$ Pharma Research and Early Development, Hoffmann-La Roche, CH-4070 Basel, Switzerland \\ ${ }^{3}$ Neuromuscular Diseases Unit/ALS Clinic, Kantonsspital St. Gallen, CH-9007 St. Gallen, Switzerland \\ ${ }^{4}$ Department of Nuclear Medicine, University Hospital Zurich, CH-8091 Zurich, Switzerland \\ $\uparrow$ Those authors contributed equally to this work
}

\section{Supplemental Information}

1) Radiochemistry

2) Positron emission tomography - The rat brain

3) NMR analysis 


\section{1) Radiochemistry}

Radioligands were purified by semi-preparative HPLC (Merck-Hitachi L2130 system), equipped with a radiodetector VRM 202 (Comecer, Netherlands) in combination with an ACE 5 C-18-300 column ( $250 \times 10.0 \mathrm{~mm}, 5 \mu \mathrm{m})$. The following gradient solvent system was used: $0.1 \% \mathrm{H} 3 \mathrm{PO} 4$ in $\mathrm{H} 2 \mathrm{O}$ (solvent A), MeCN (solvent B); 0.0$8.0 \mathrm{~min}, 20 \% \mathrm{~B} ; 8.1-30.0 \mathrm{~min}, 20-90 \% \mathrm{~B} ; 30.1-35.0 \mathrm{~min}, 90 \% \mathrm{~B} ; 35.1-37.0 \mathrm{~min}, 90-20 \% \mathrm{~B} ; 37.1-43.0 \mathrm{~min}, 20 \% \mathrm{~B}$. A flow rate of $4 \mathrm{~mL} / \mathrm{min} \mathrm{was}$ used, the UV signal detection was conducted at $230 \mathrm{~nm}$. Analytical quality control was carried out on an Agilent 1100 series HPLC system, equipped with UV-detector and a GabiStar radiodetector (Raytest). A reverse phase ACE C18-AR column $(50 \times 4.6 \mathrm{~mm}, 3 \mathrm{~mm})$ was used with the following separation conditions: $0.1 \%$ TFA in $\mathrm{H} 2 \mathrm{O}$ (solvent A), MeCN (solvent B); 0.0-2.0 min, 20\% B; 2.1-12.0 min, 20-90\% B; 12.1-14.0 min, 90\% B; 14.1-15.0 min, 90-20\% B; 15.1-20.0 min, 20\% B, flow rate of 1 mL/min and UV signal detection at $320 \mathrm{~nm}$.
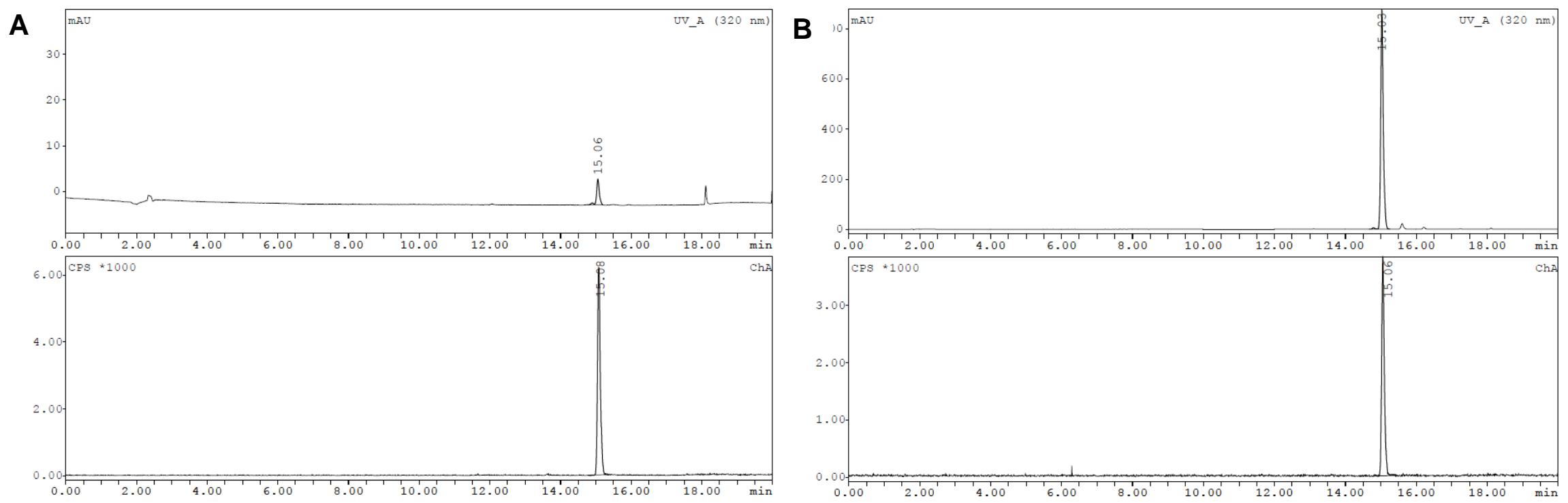

Supplemental Figure 1: Representative analytical quality control of the final $\left[{ }^{18} \mathrm{~F}\right] \mathbf{3}$ formulation. A. Final formulation immediately after radiosynthesis. B. Final formulation after addition of an excess non-radioactive reference compound $\mathbf{3}$ (co-injection). 
2) Positron emission tomography with $\left[{ }^{18} \mathrm{~F}\right] 3$ - The rat brain

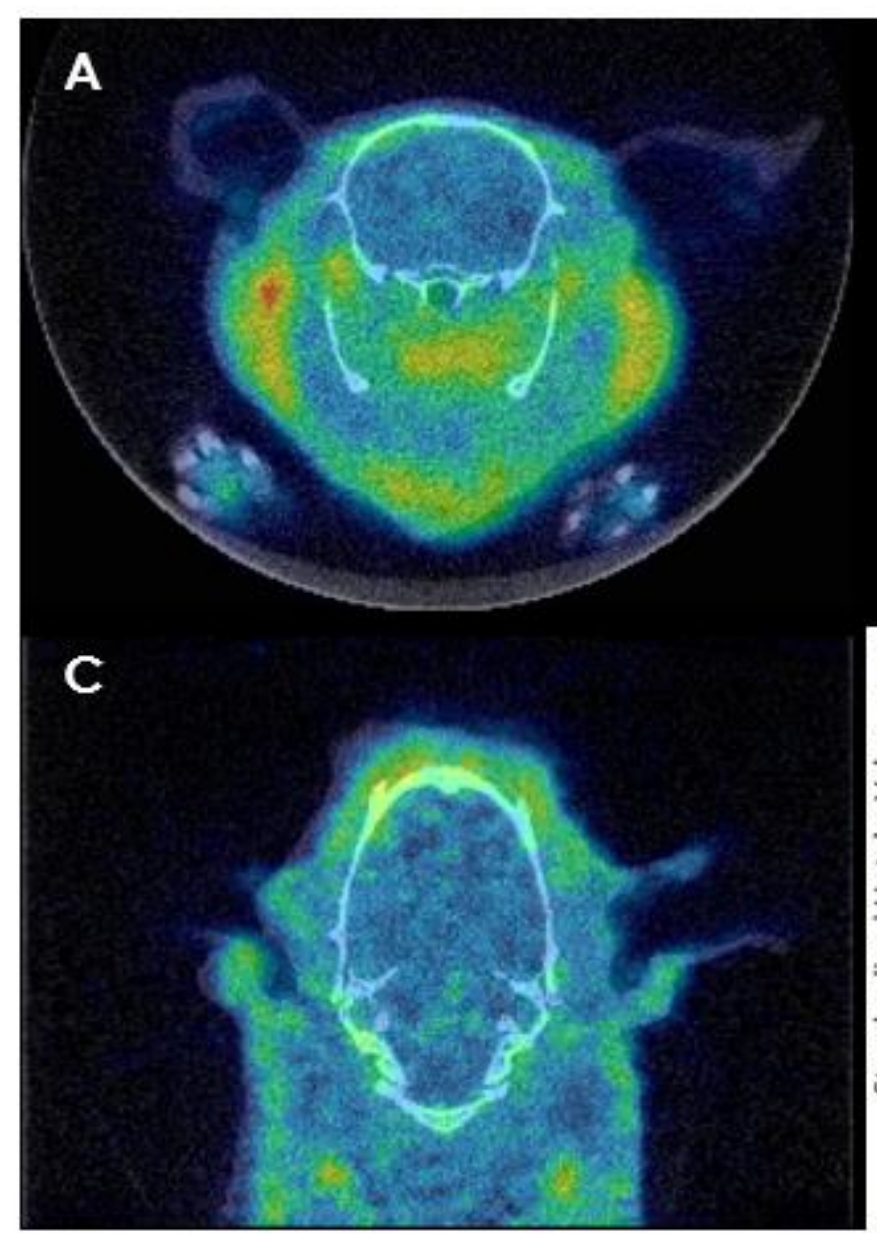

B

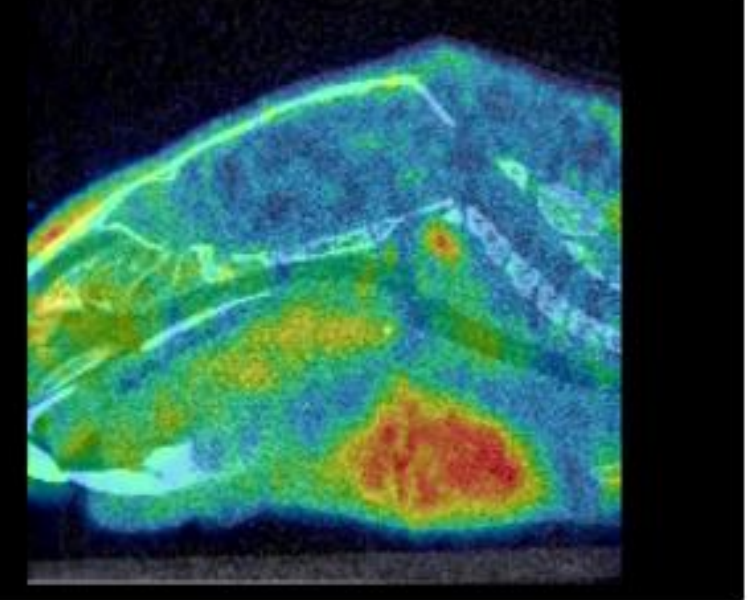

$D_{1.0}$

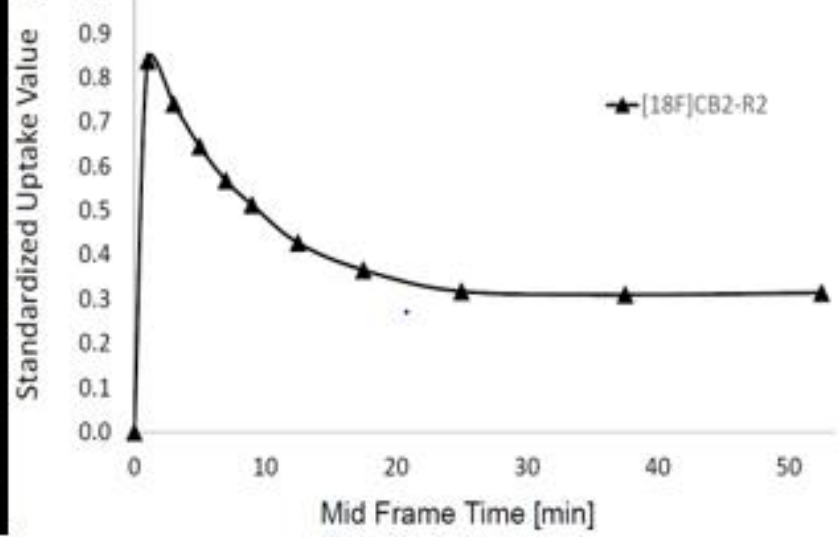

Supplemental Figure 2: PET images, averaged from the initial 10 min post injection, and time-activity curve of the healthy Wistar rat brain after tail-vein injection of $\left[{ }^{18} \mathrm{~F}\right]$ 3. A. Transaxial view. B. Sagittal view. C. Coronal view. D. Time-activity curve of the whole brain. 


\section{3) NMR analysis}

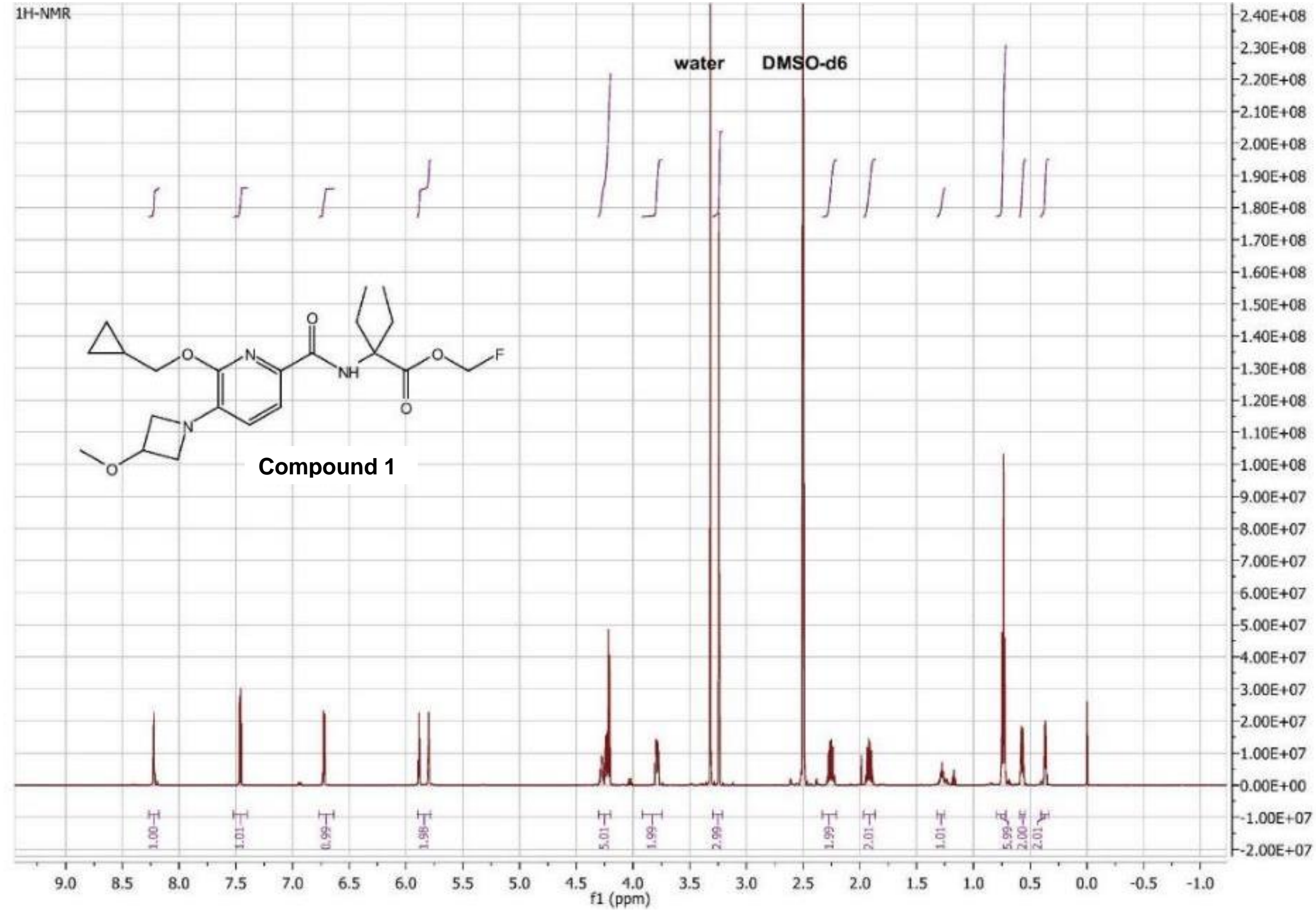




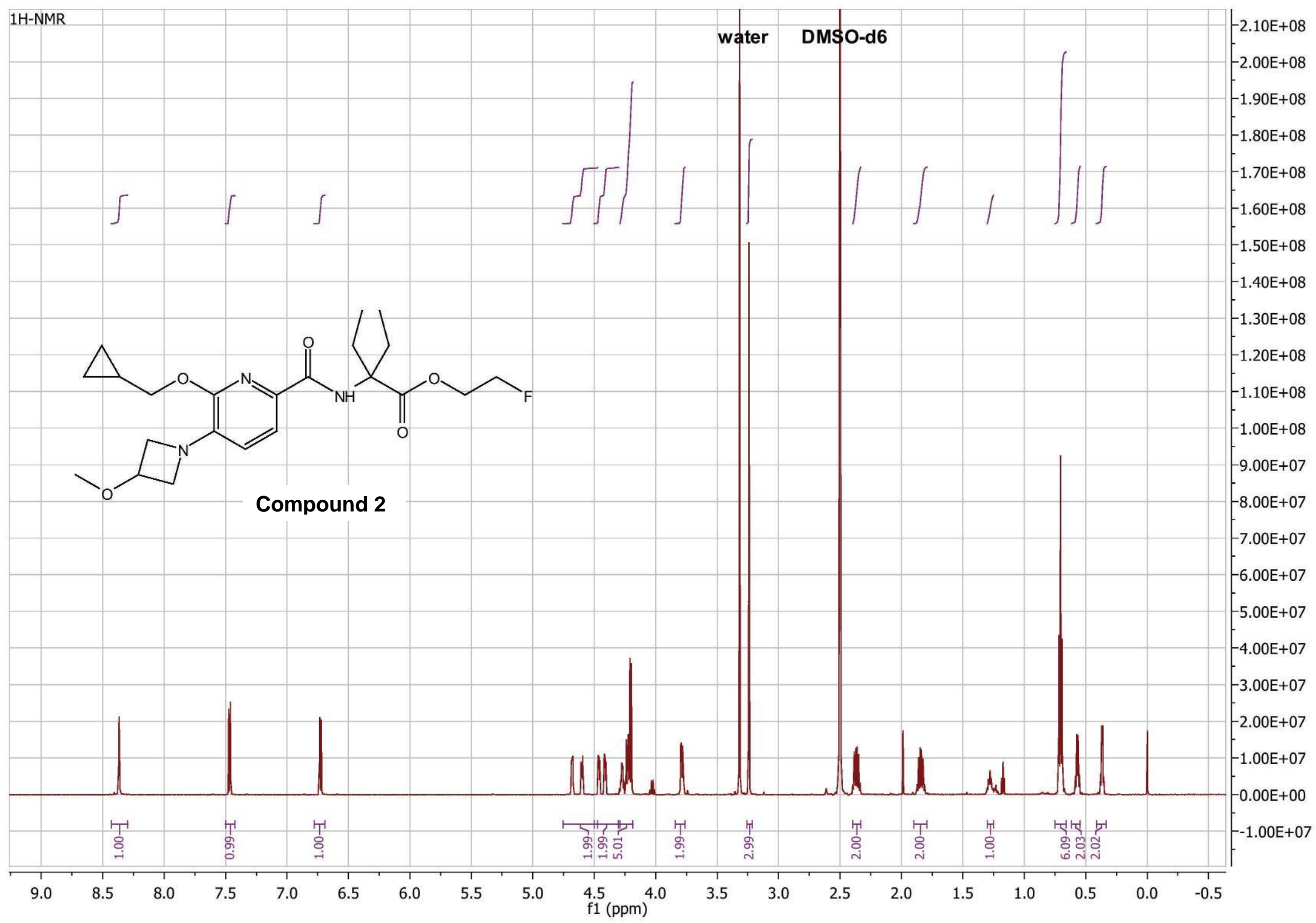




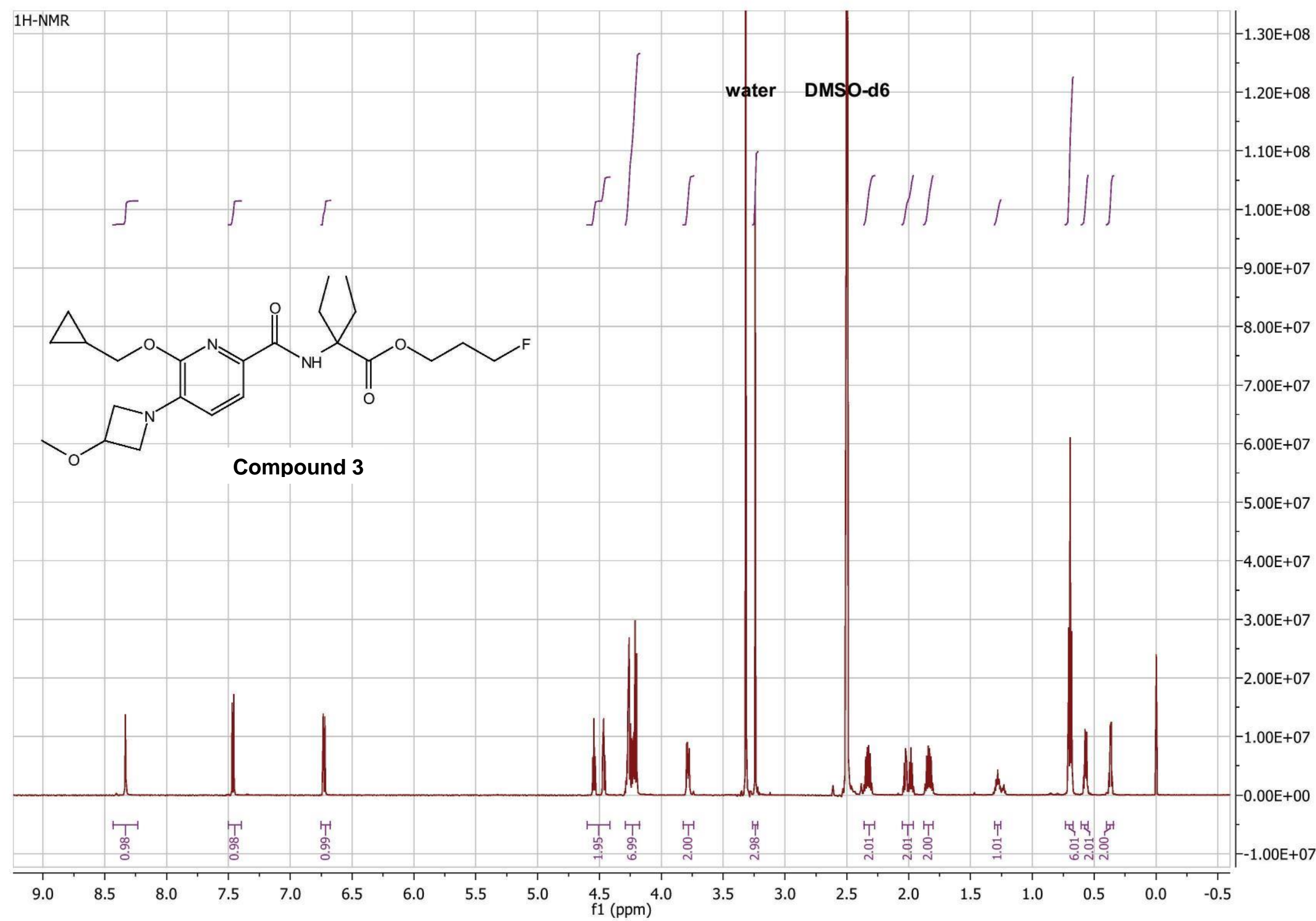




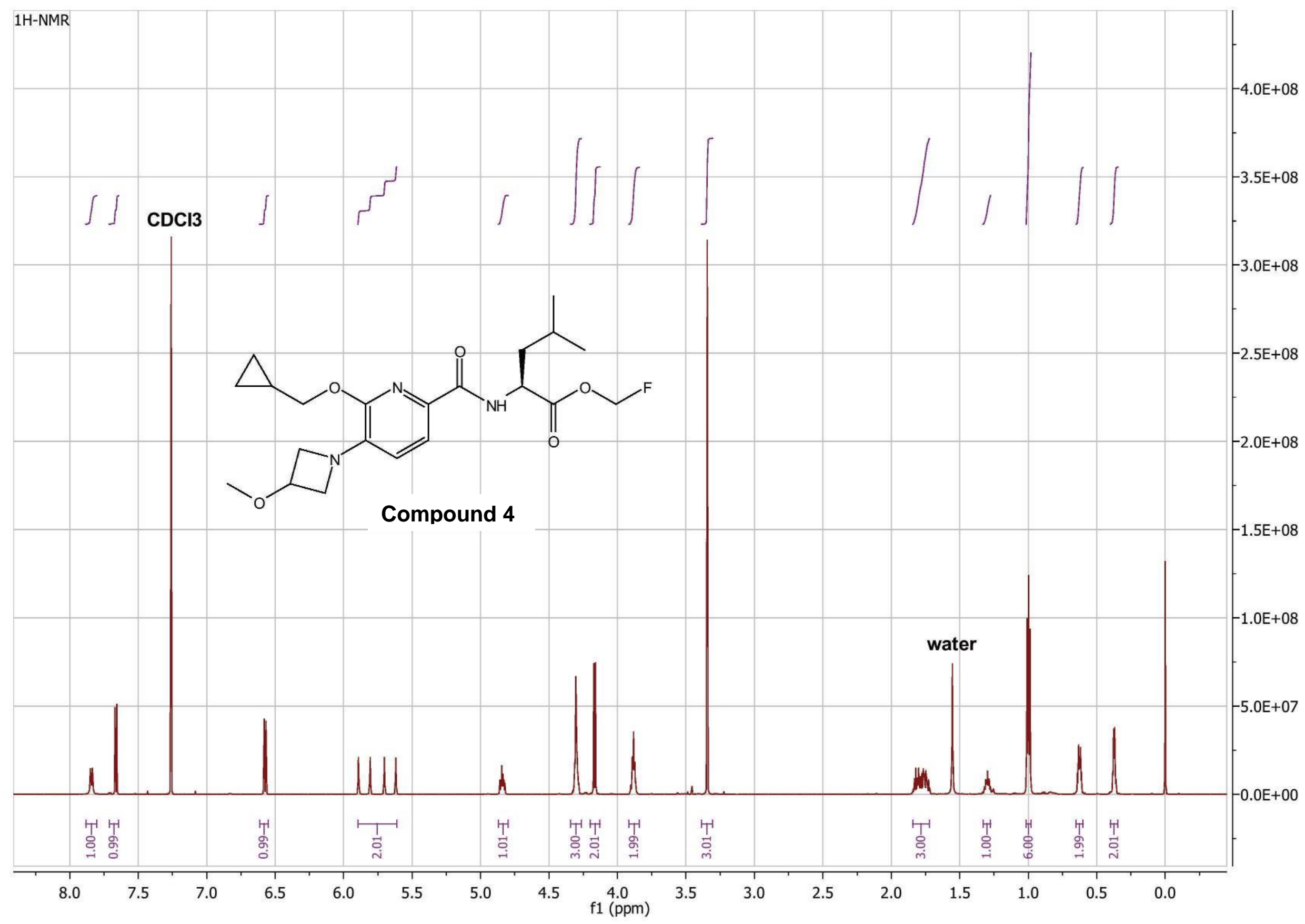




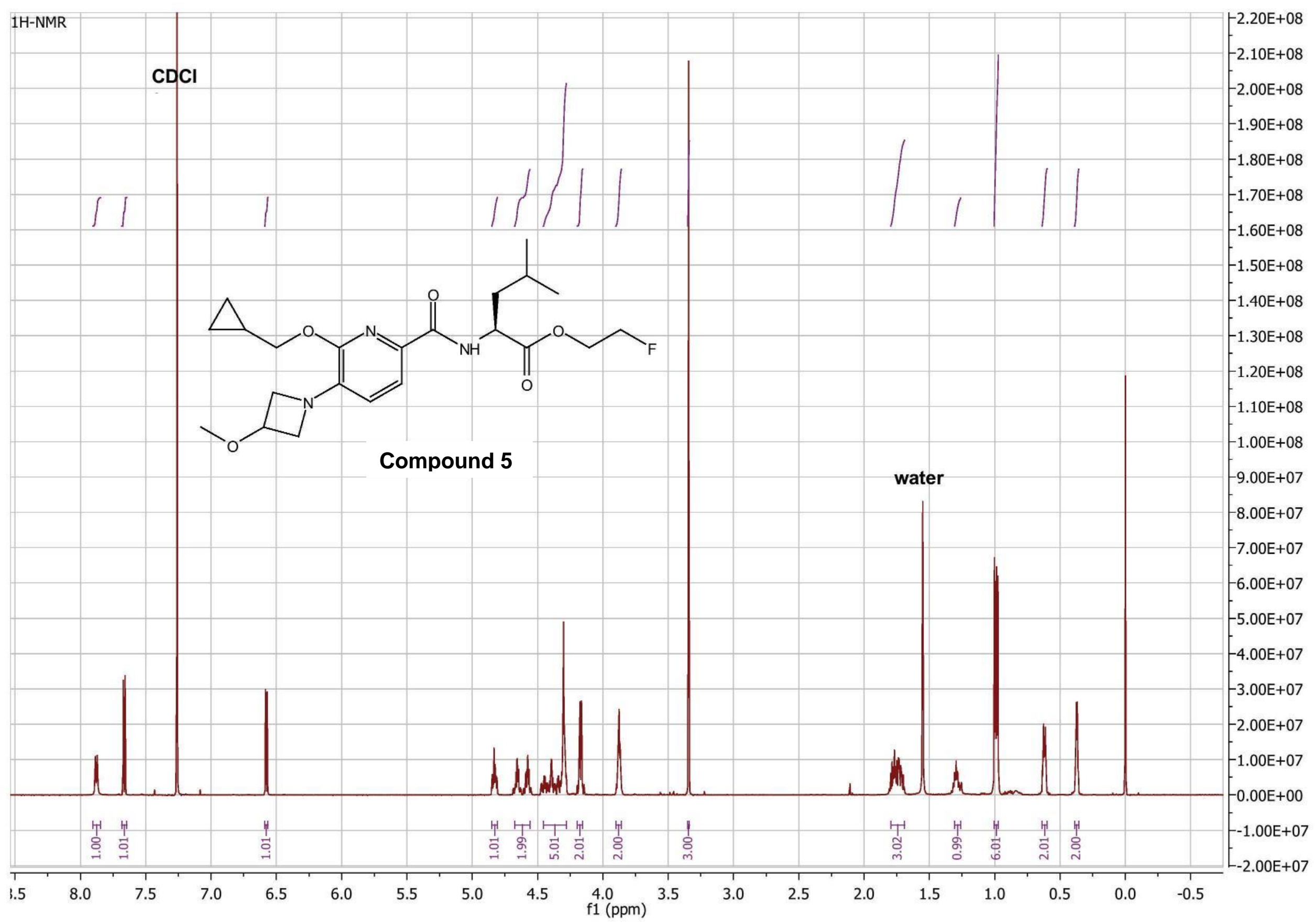




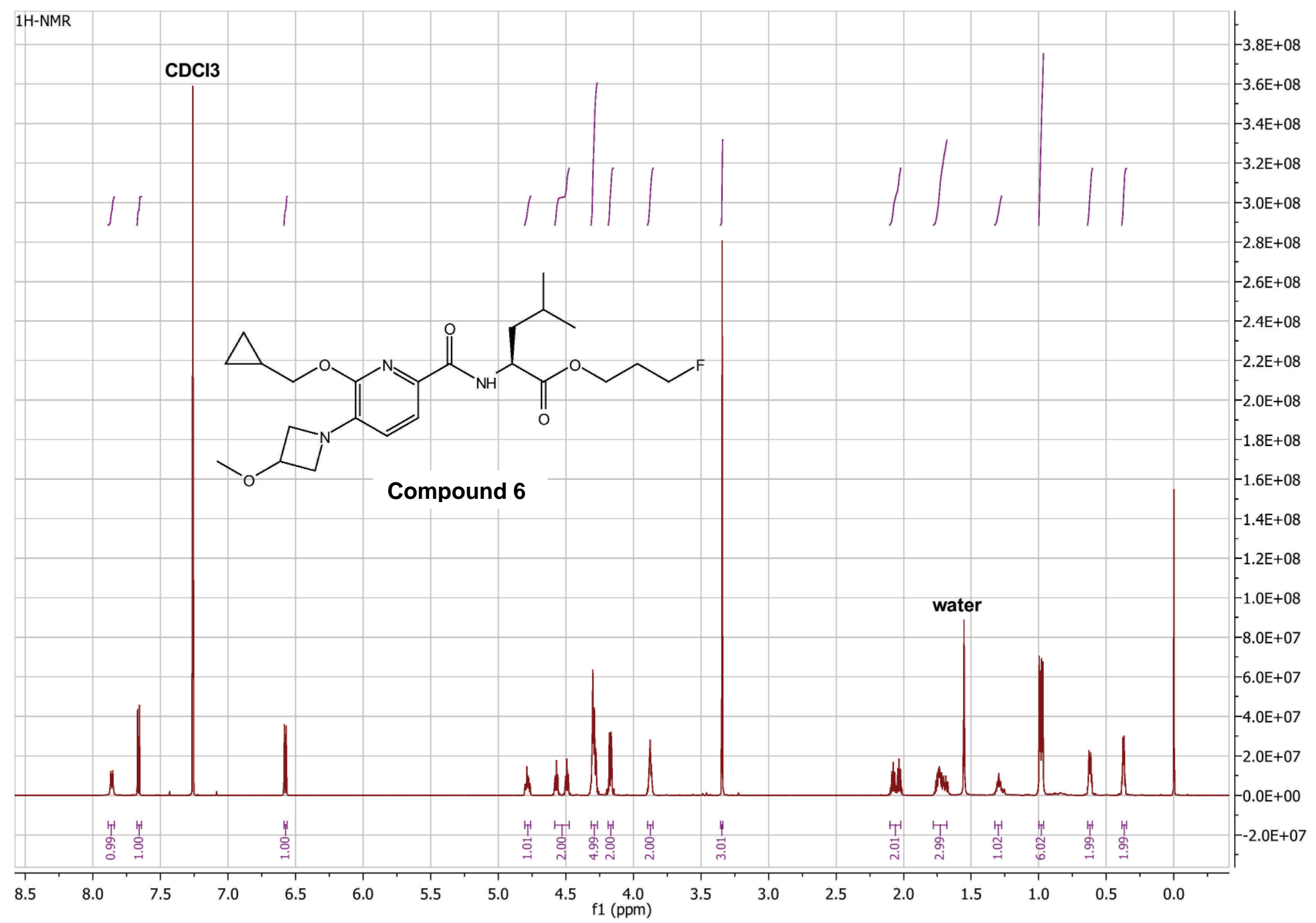




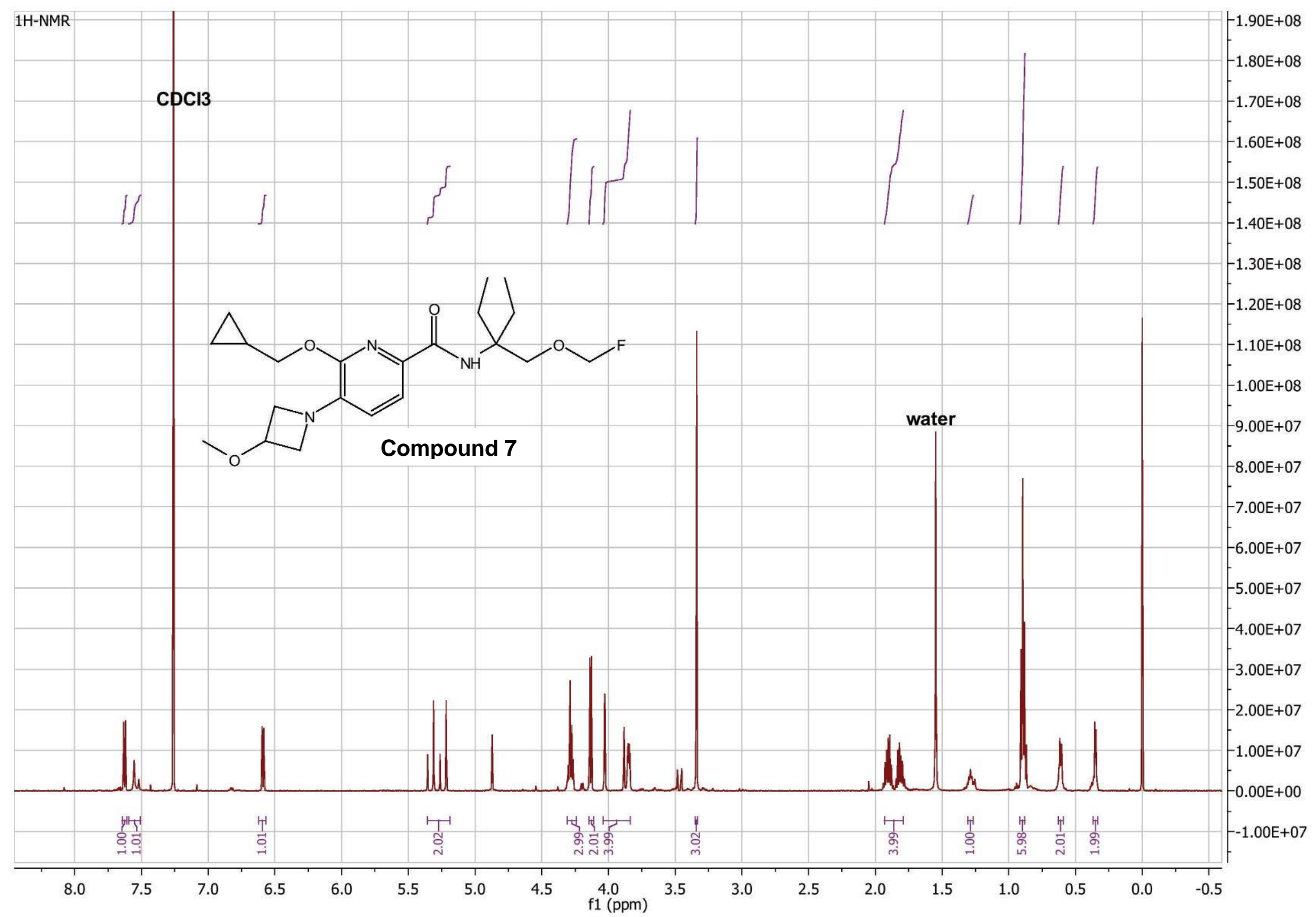




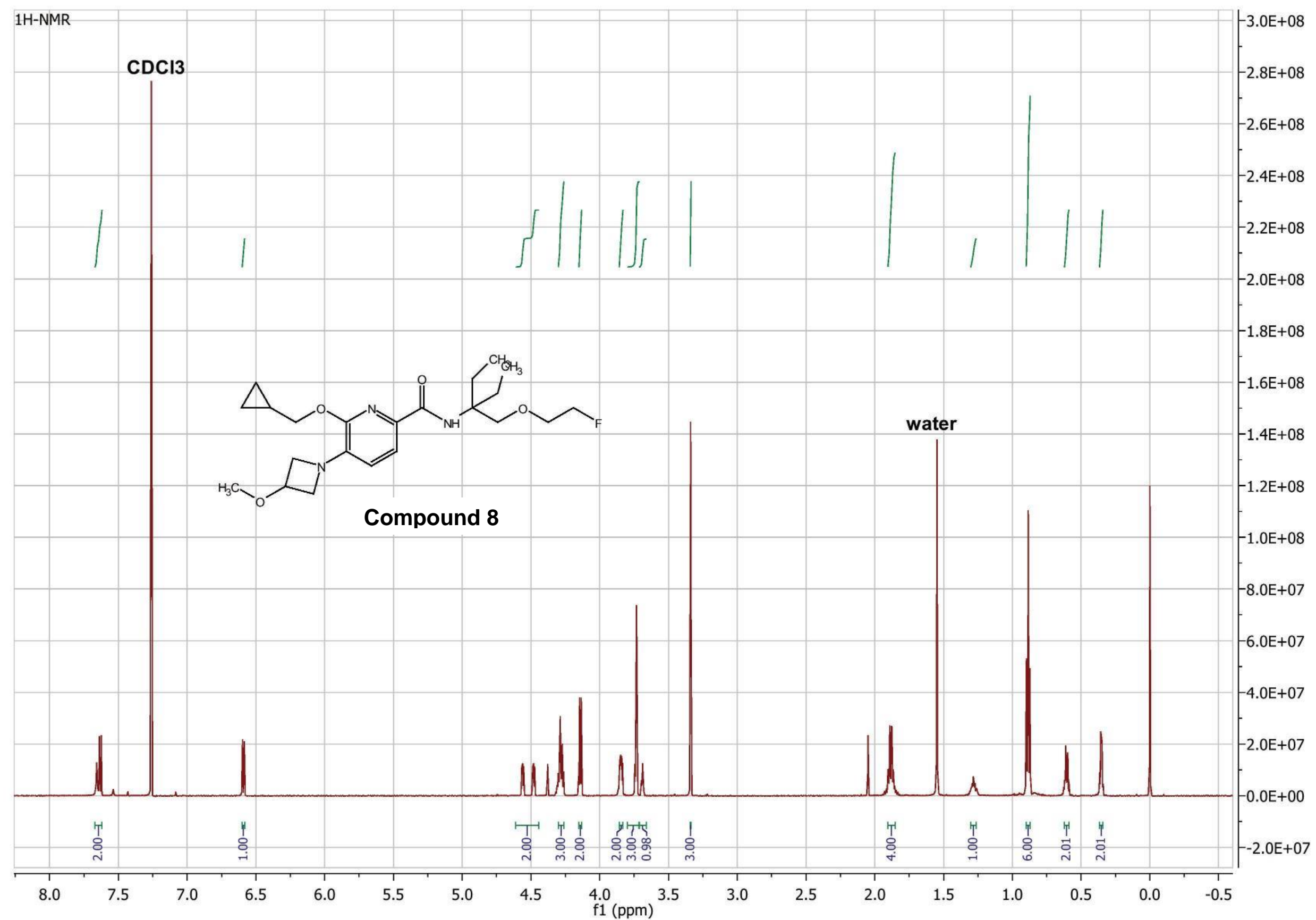




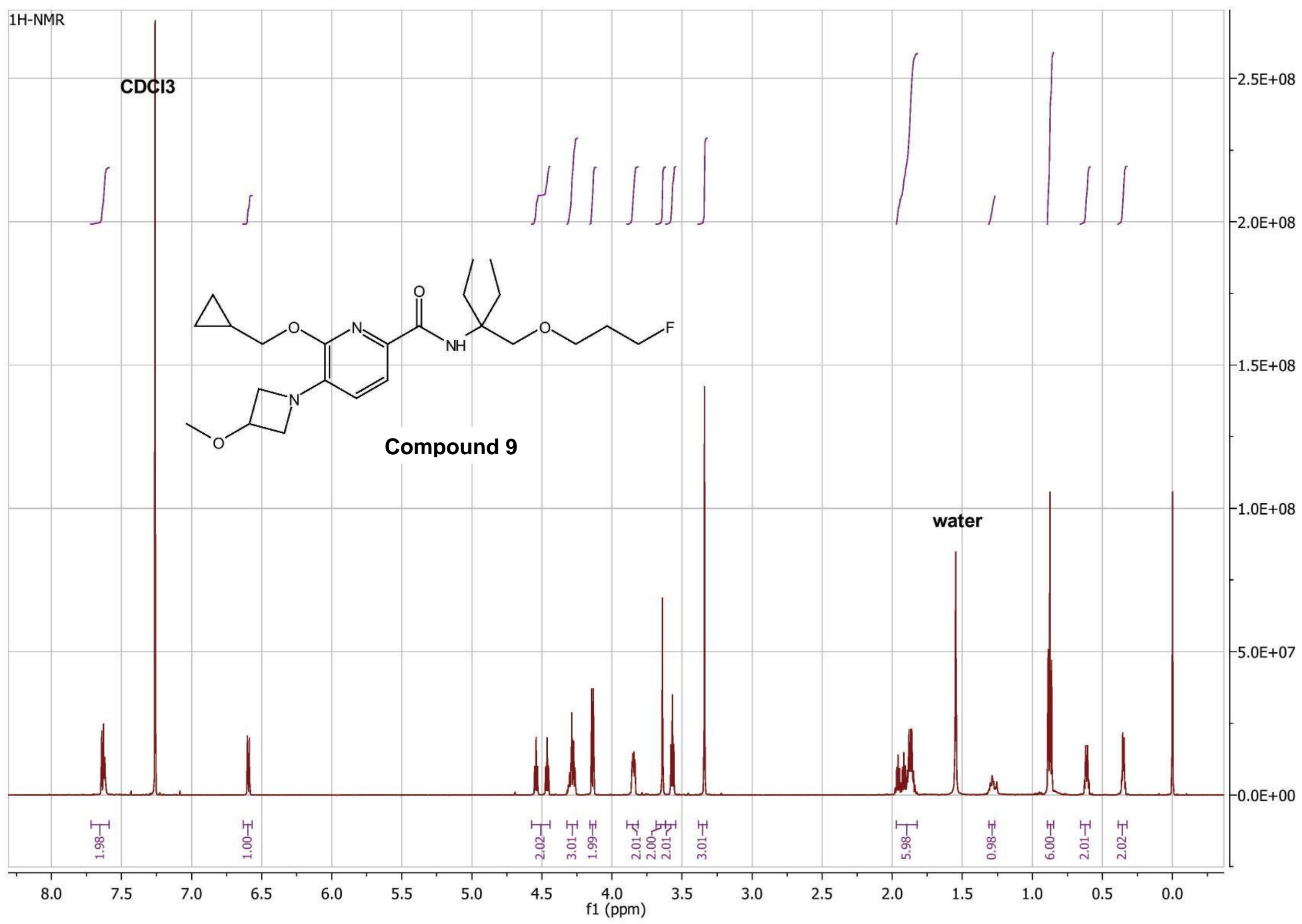




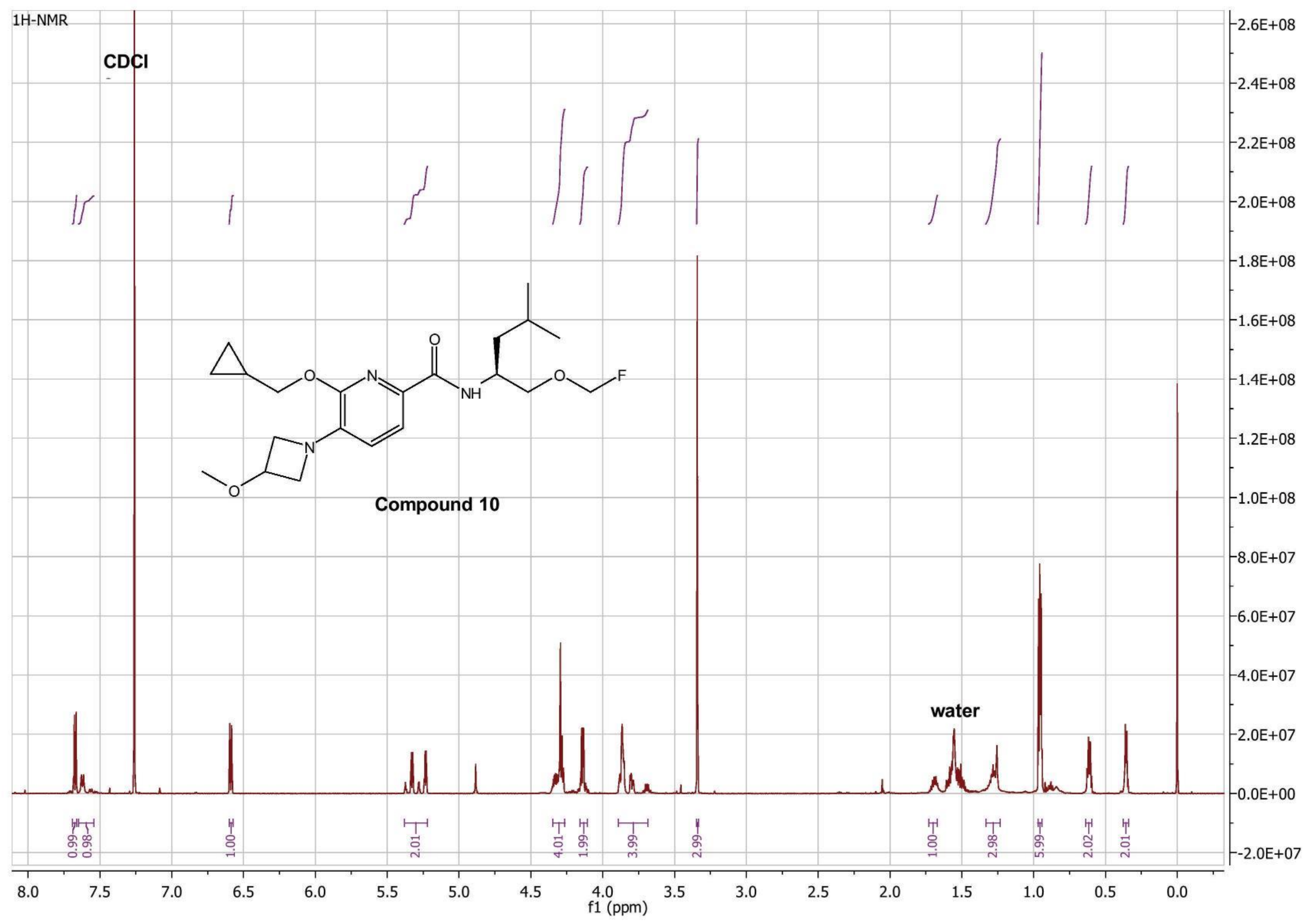




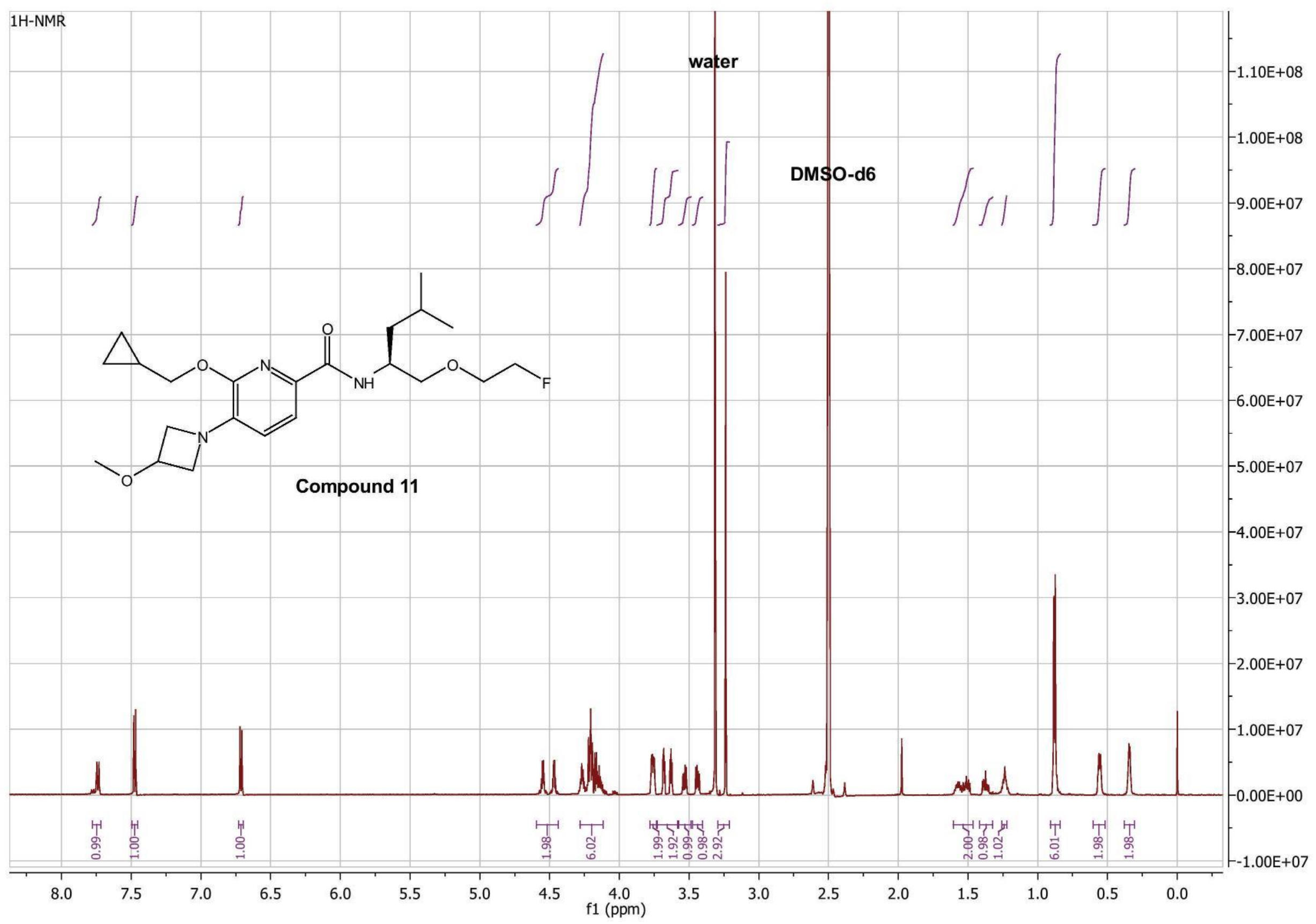




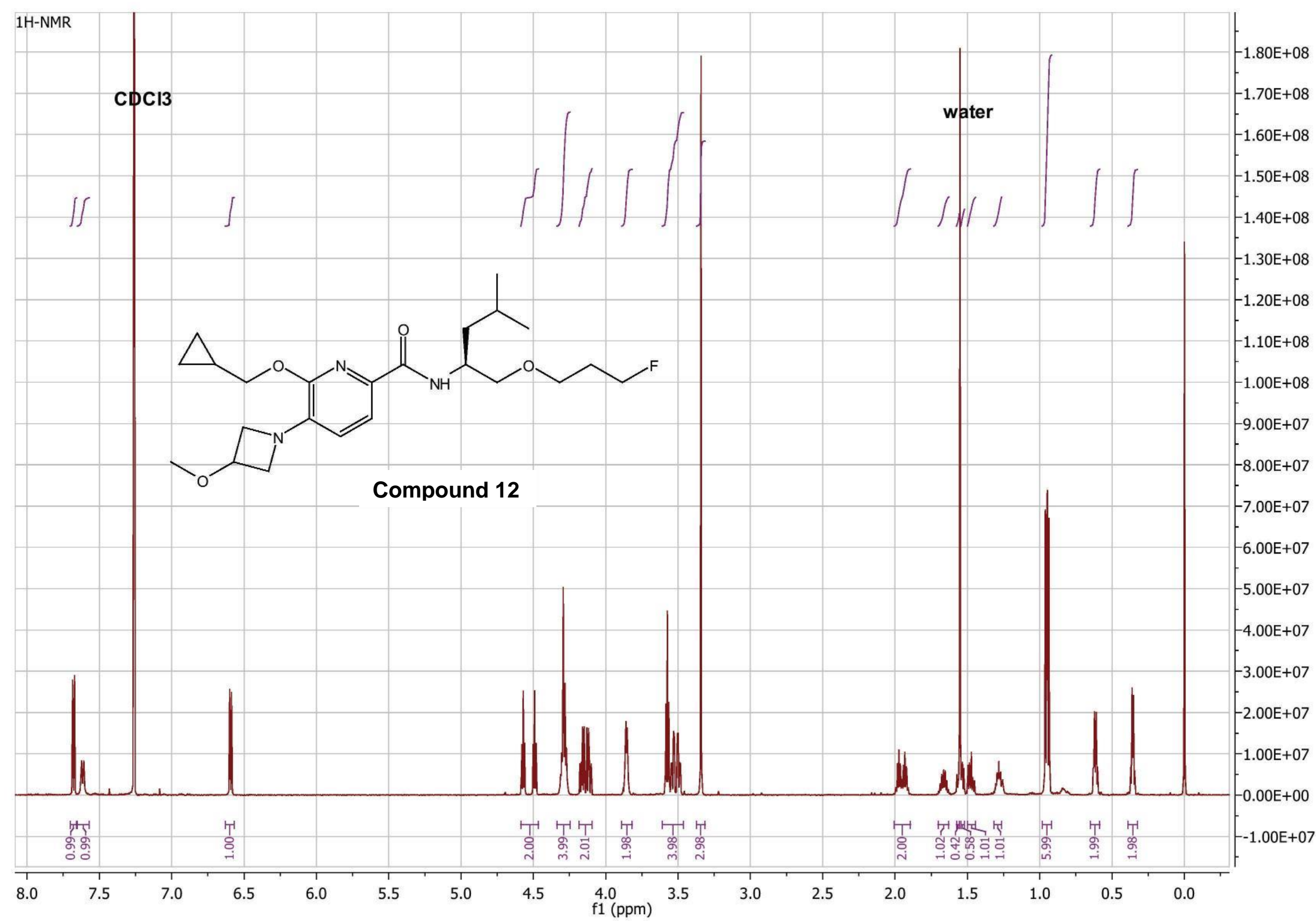




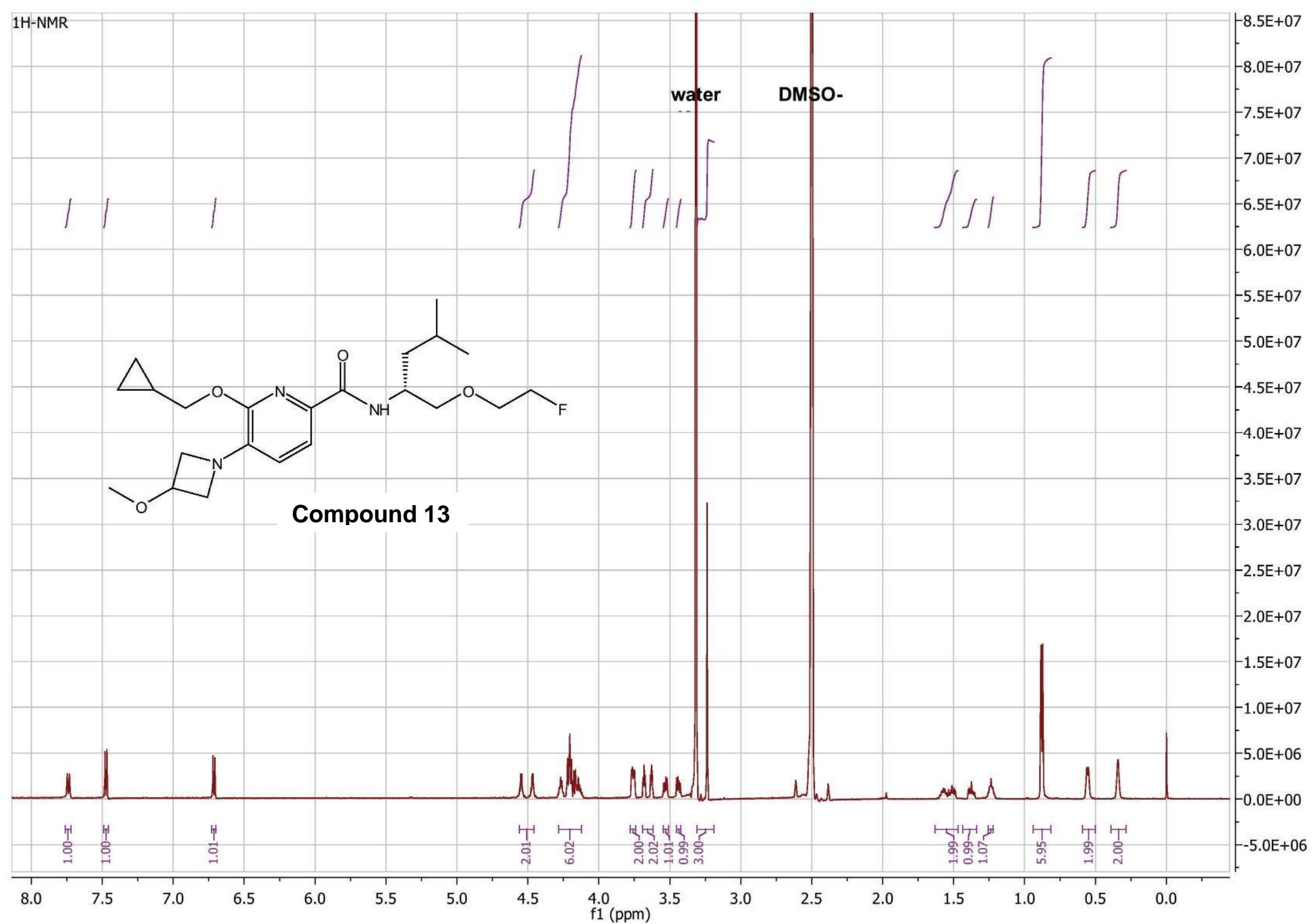




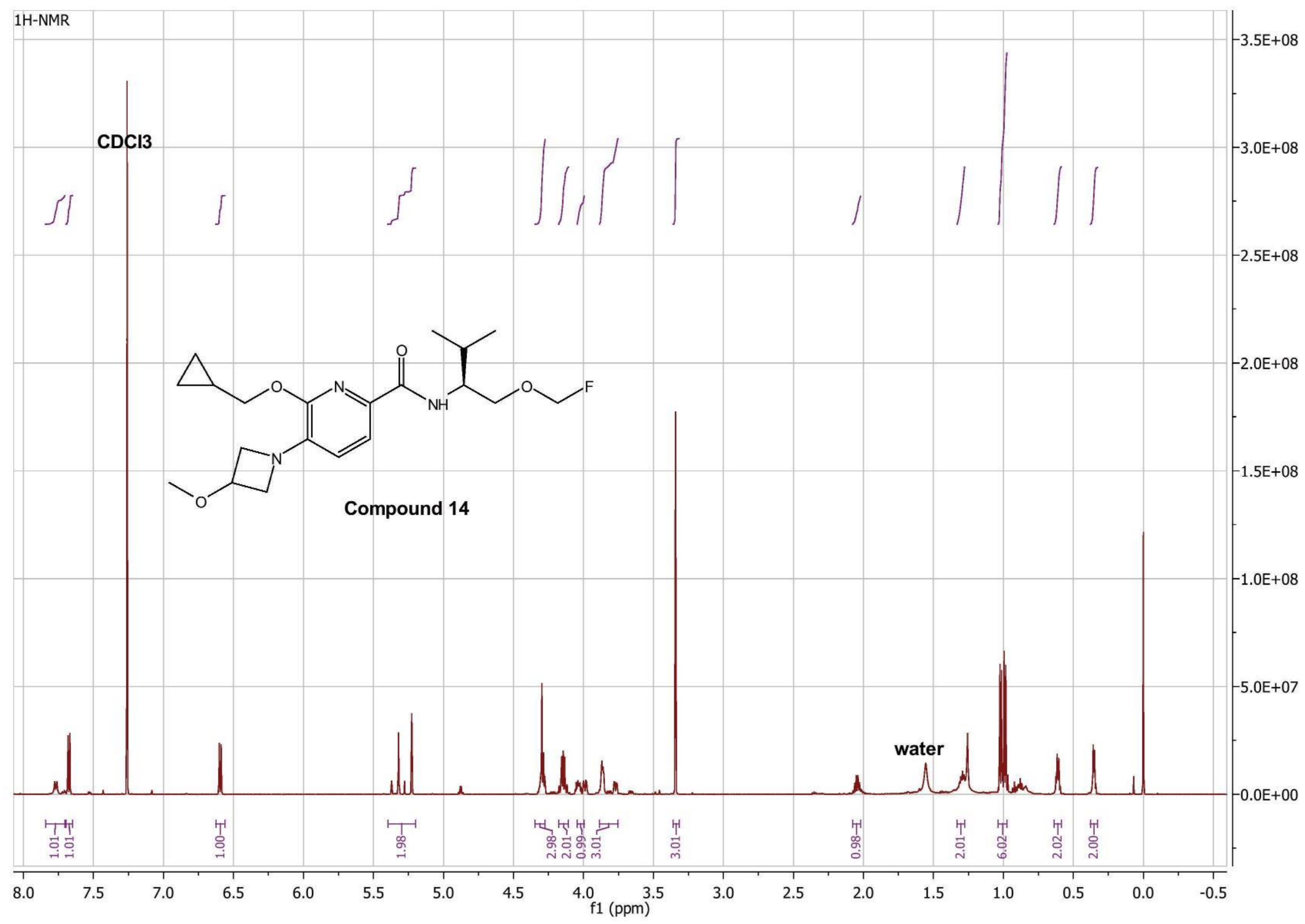




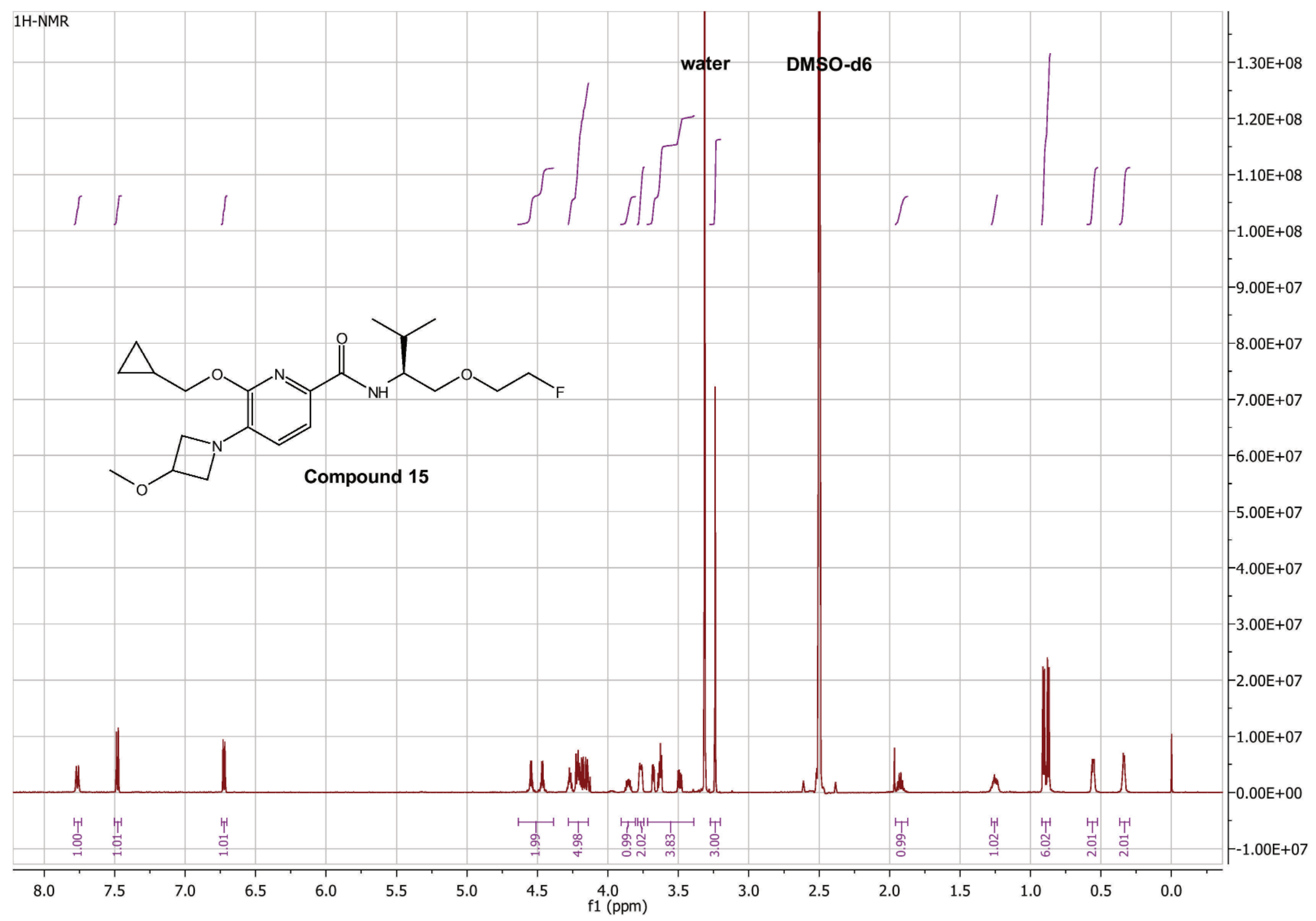









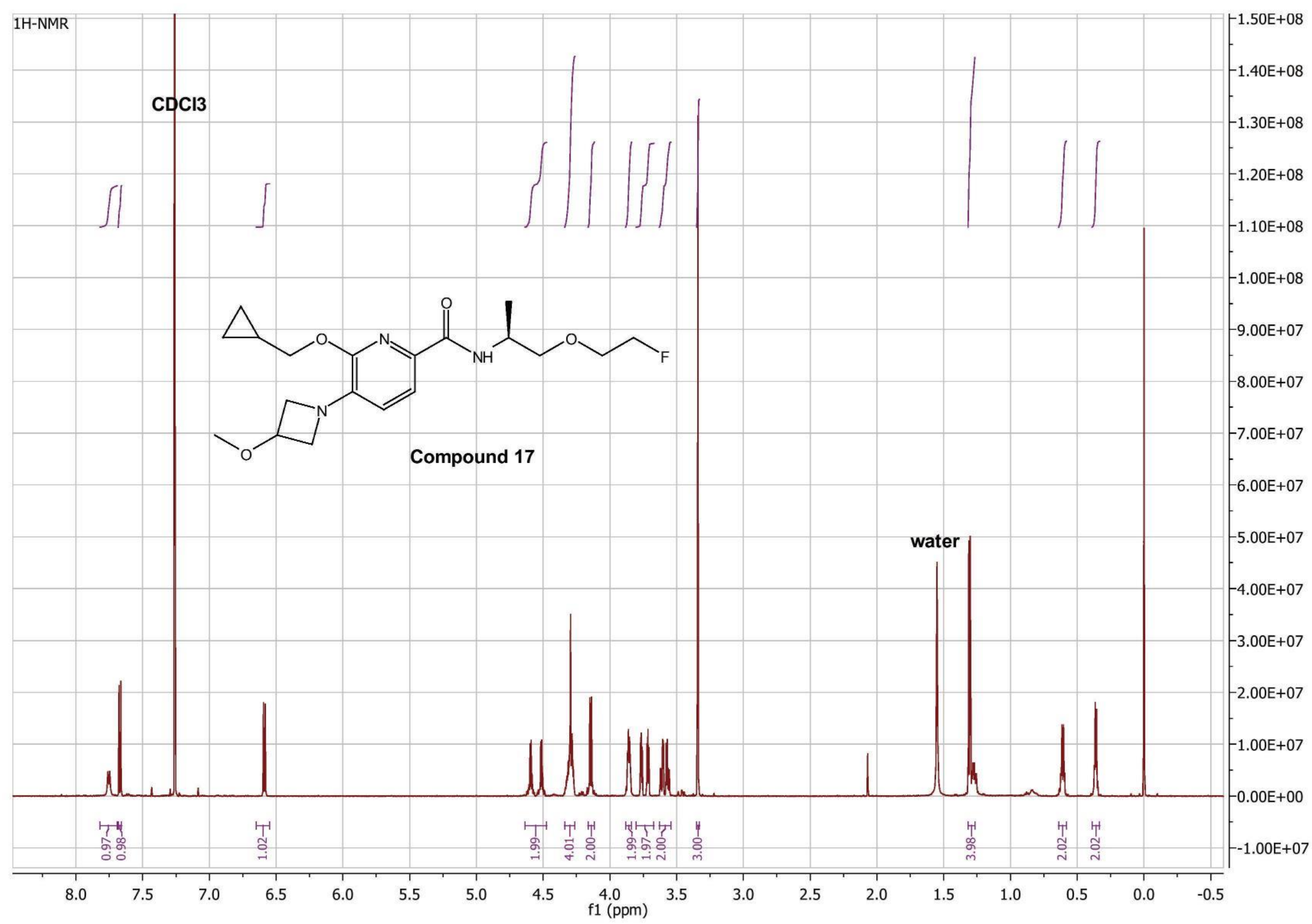




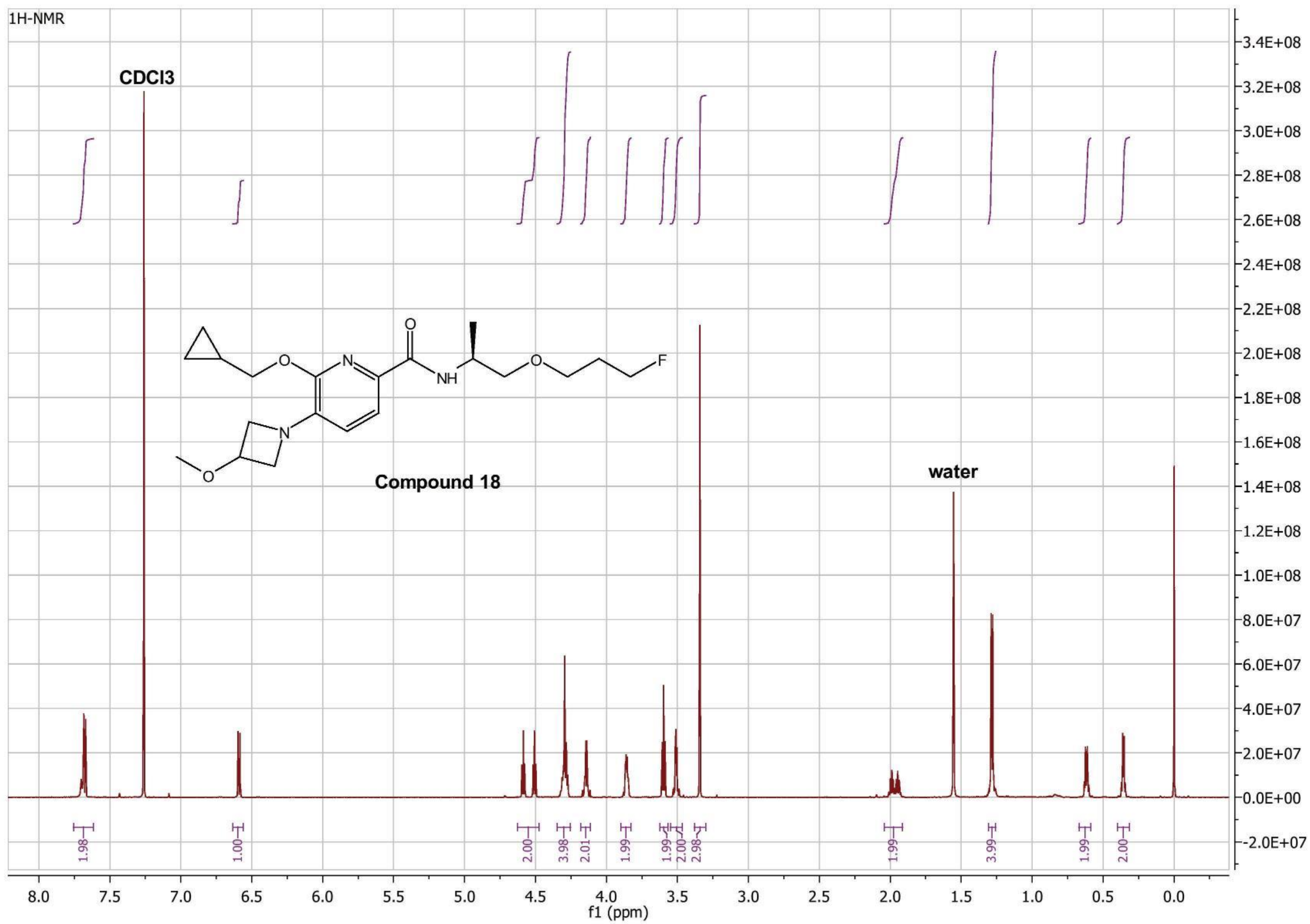




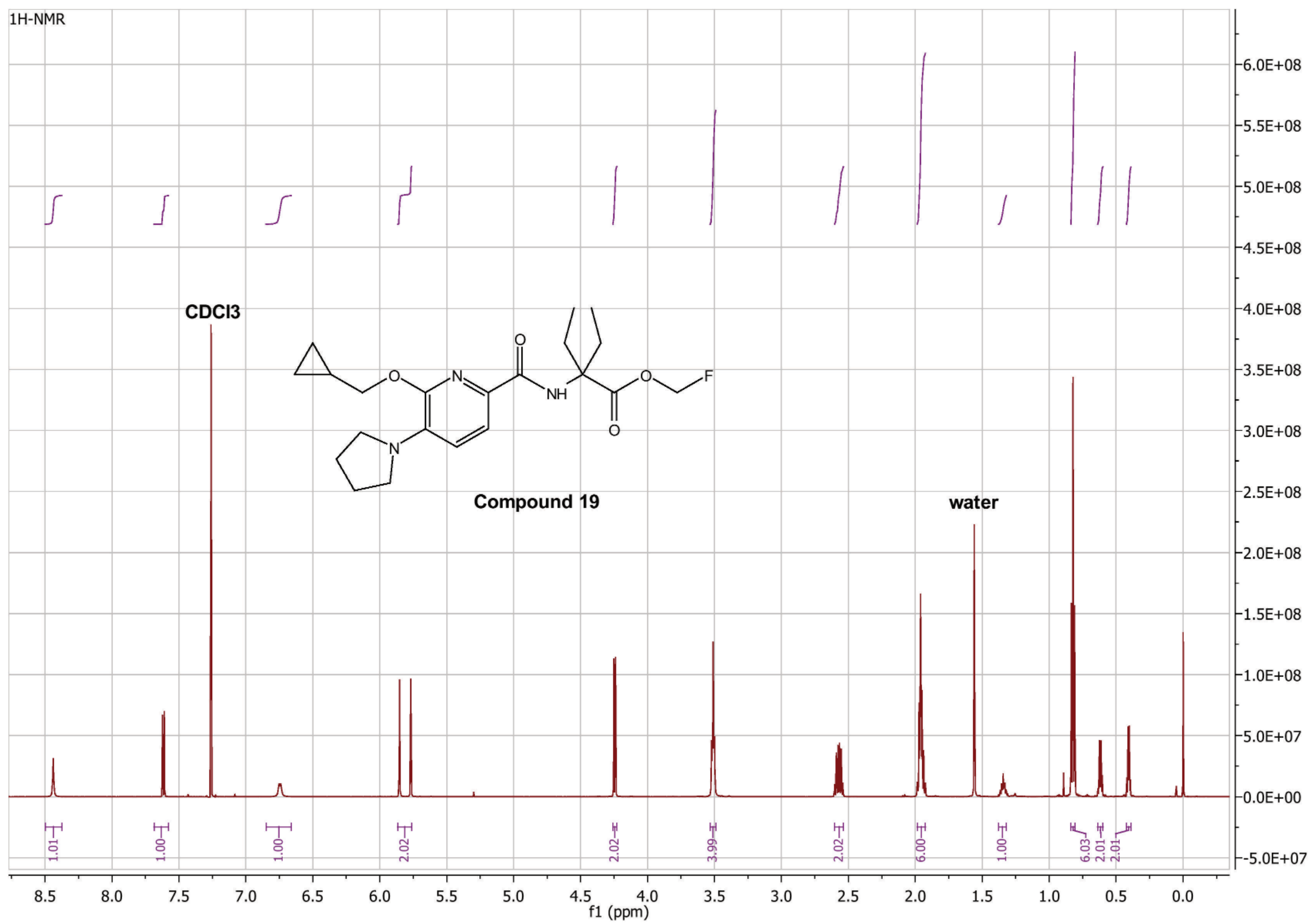




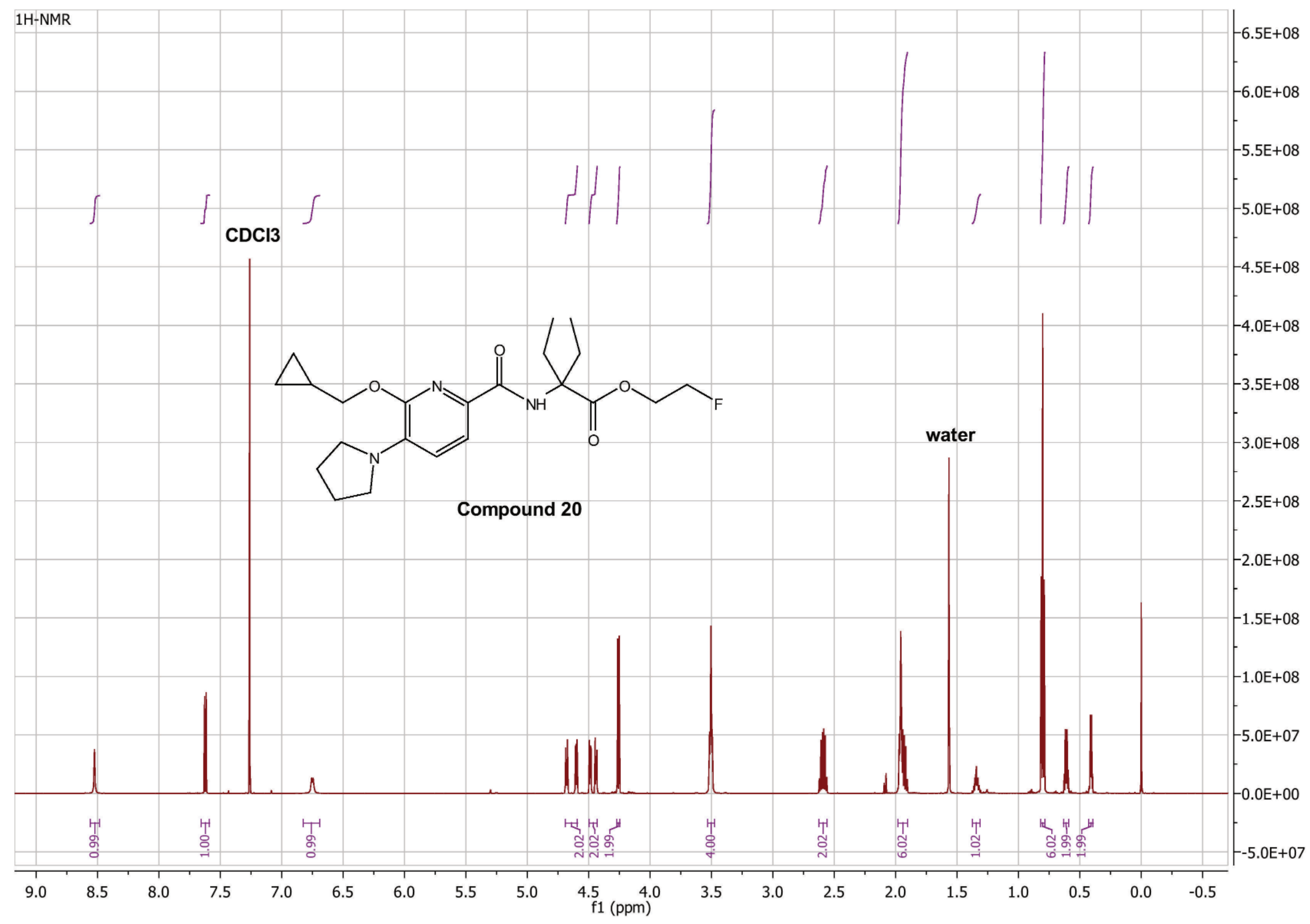




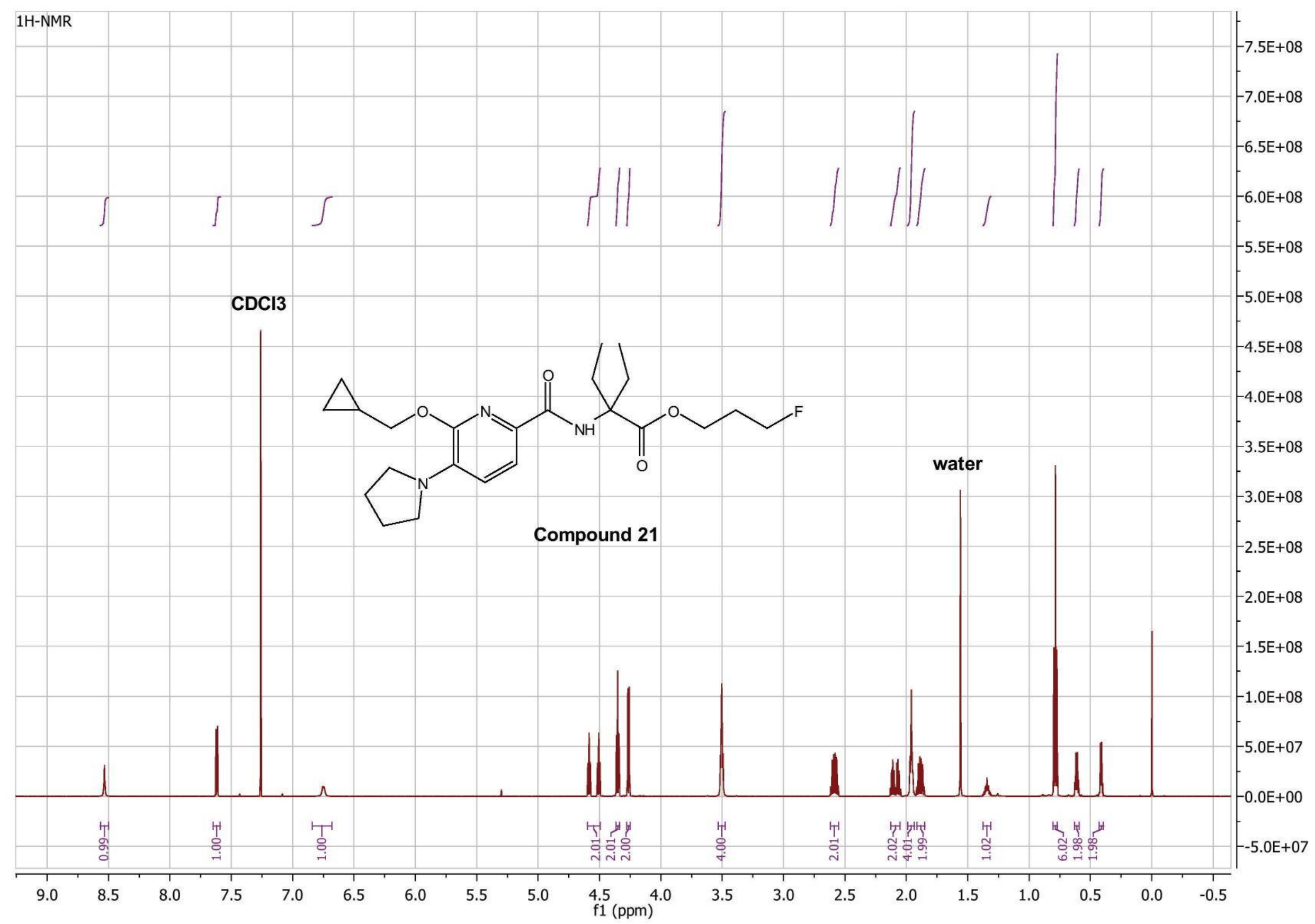




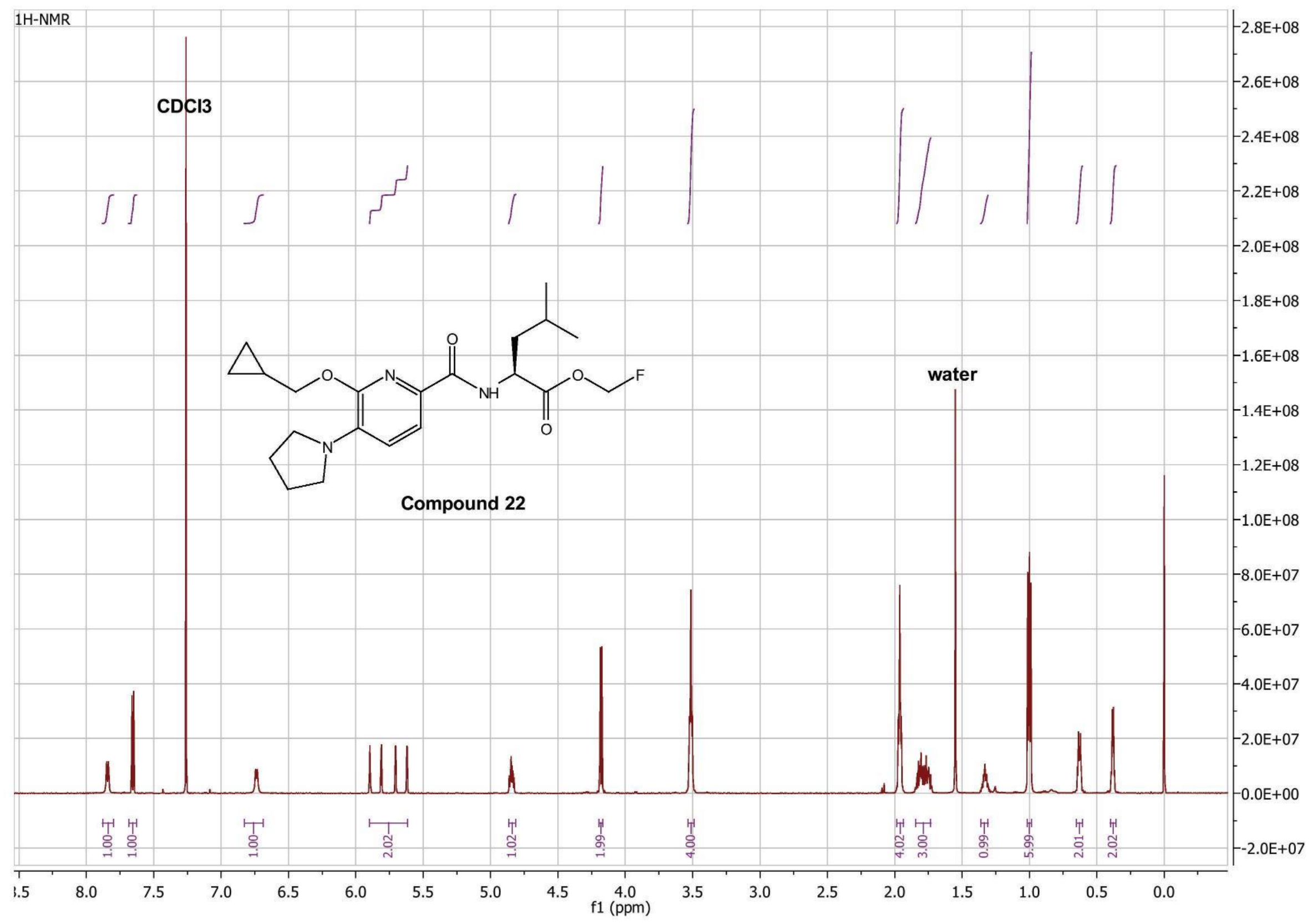




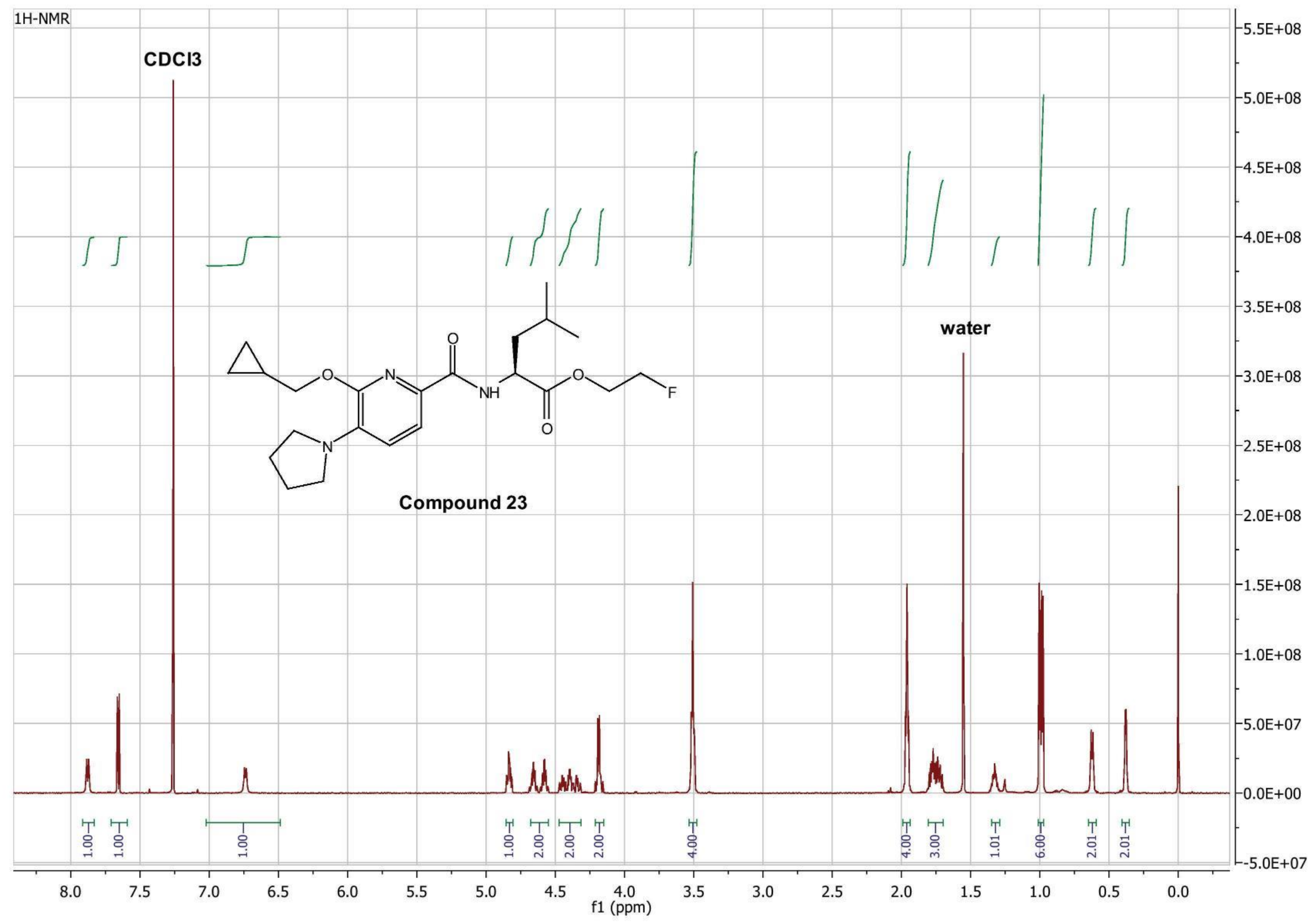




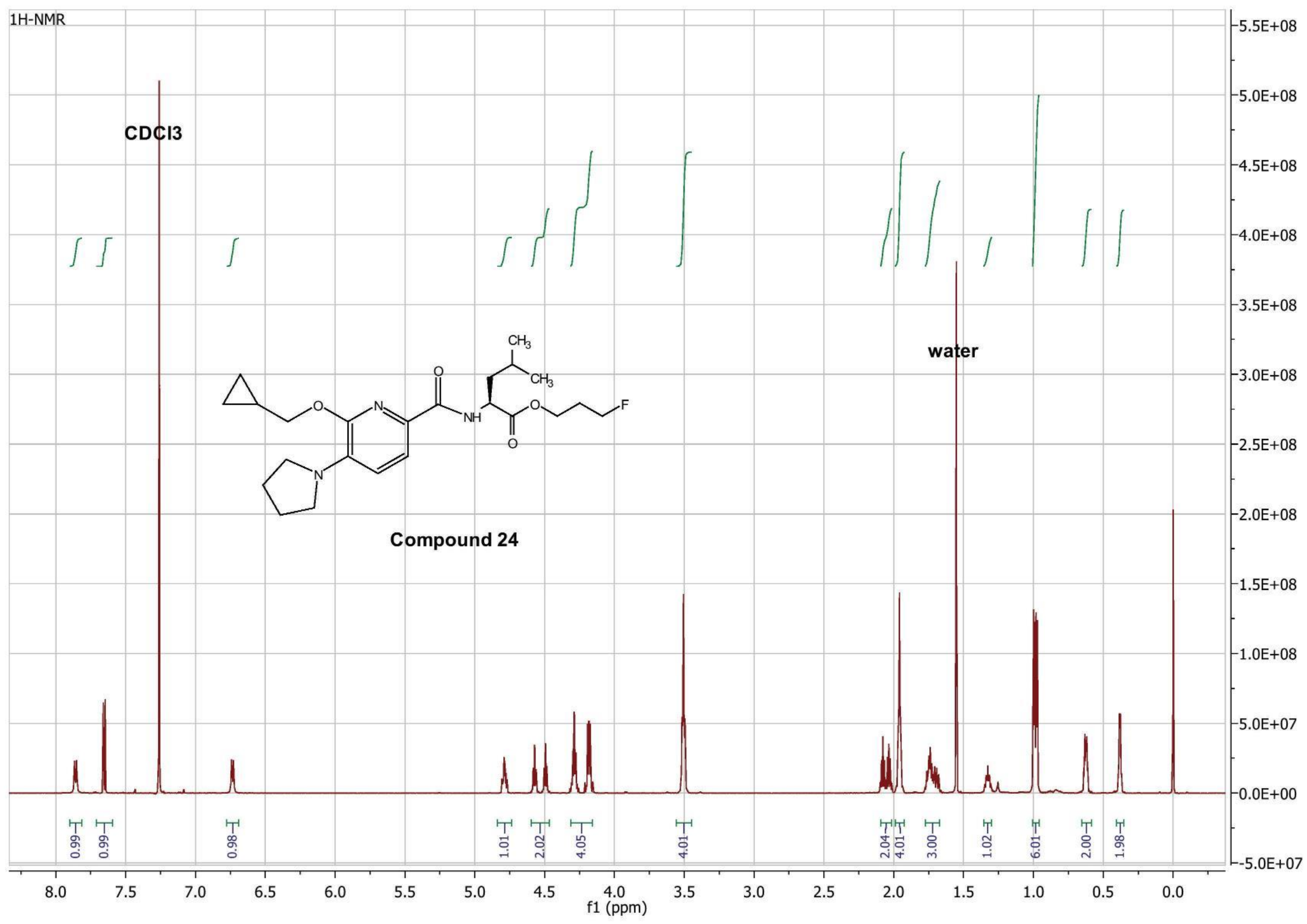




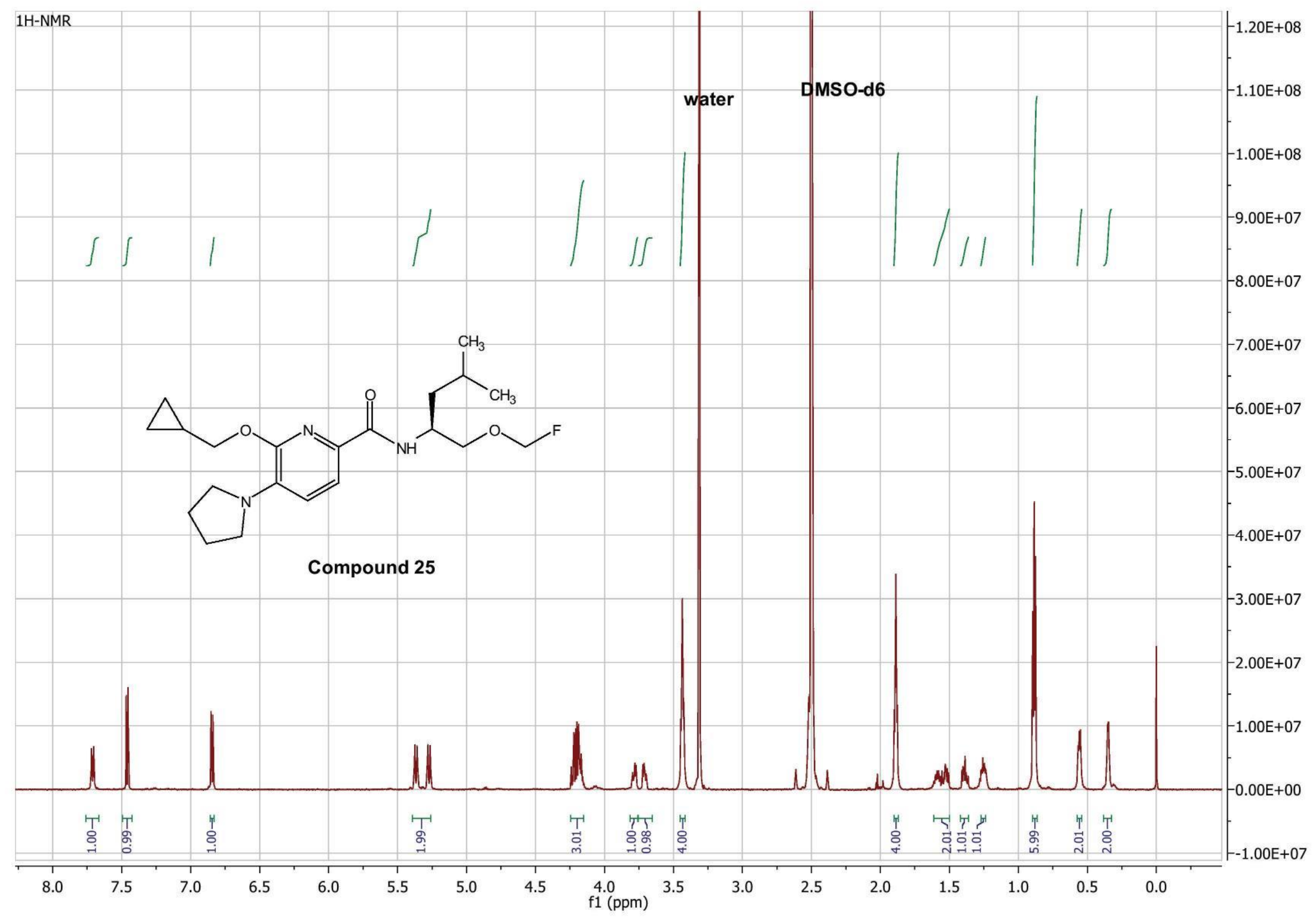




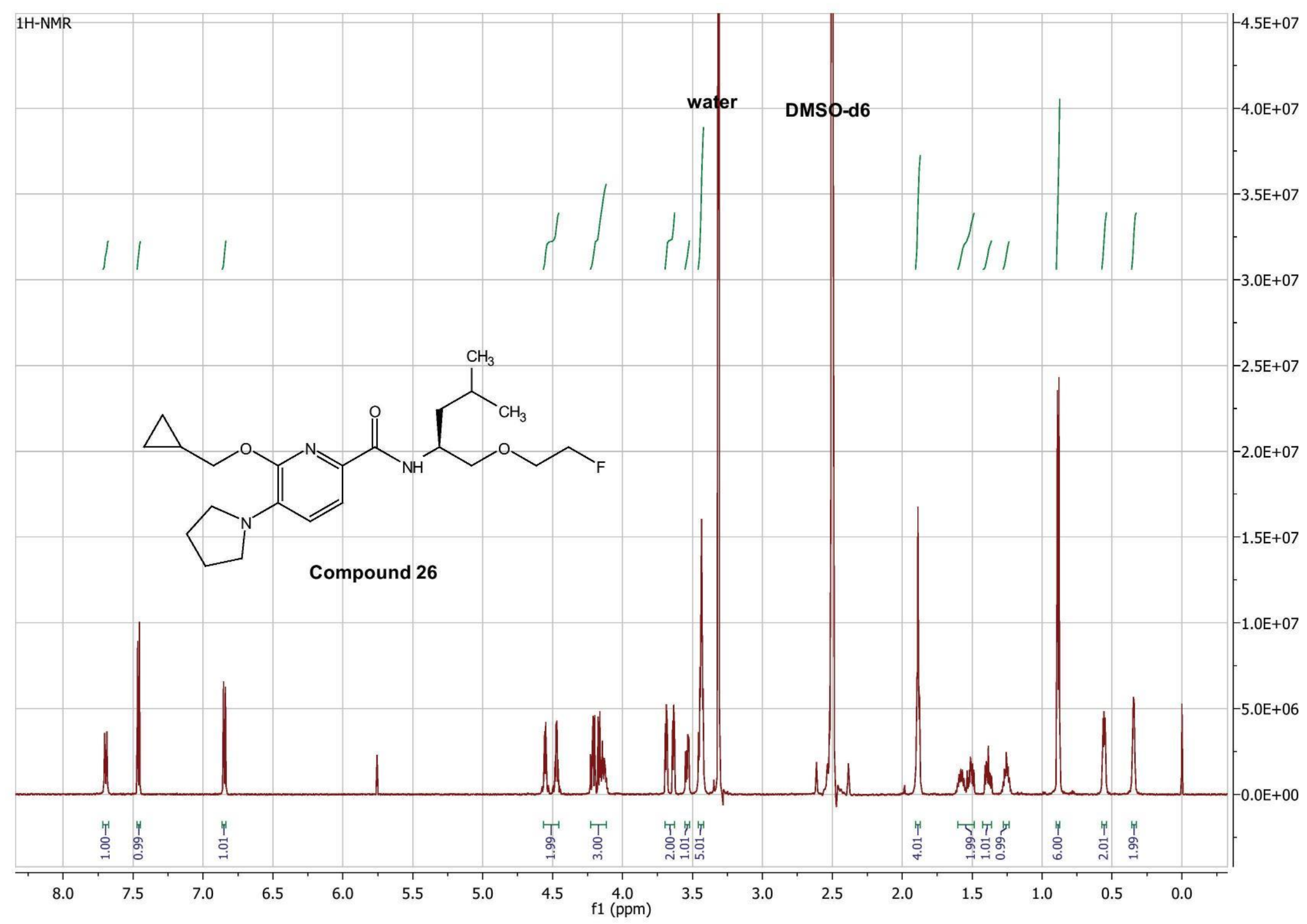




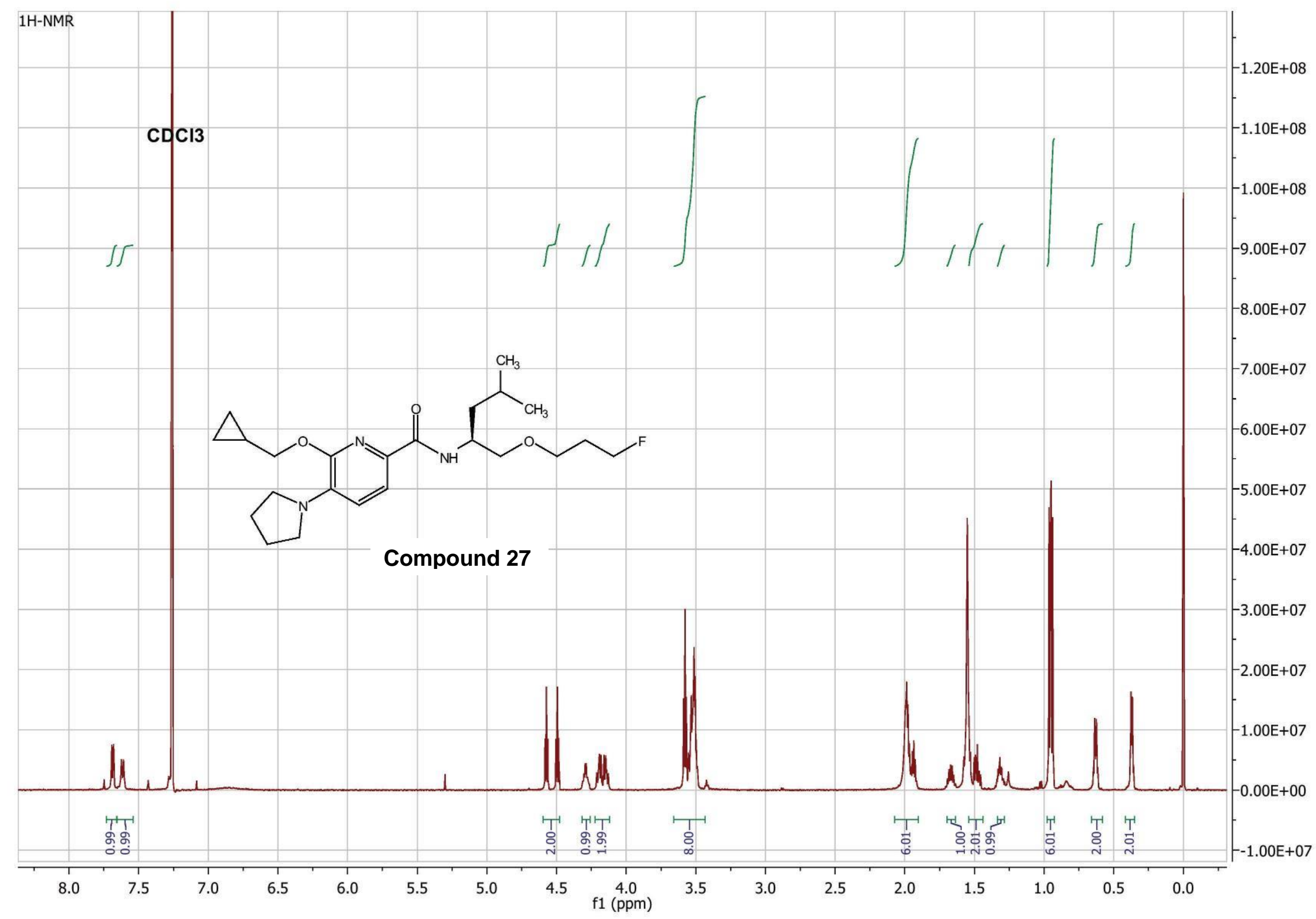




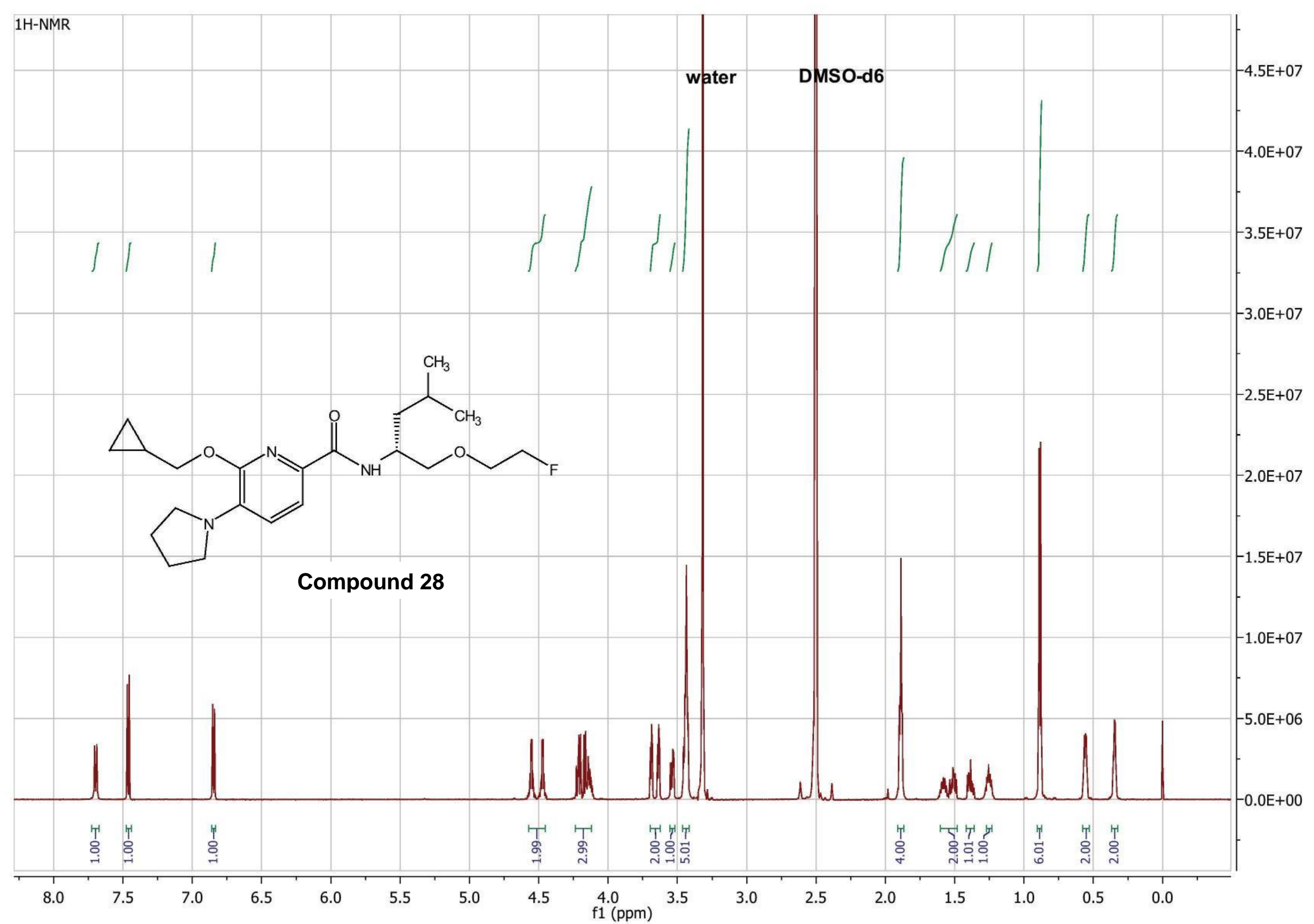




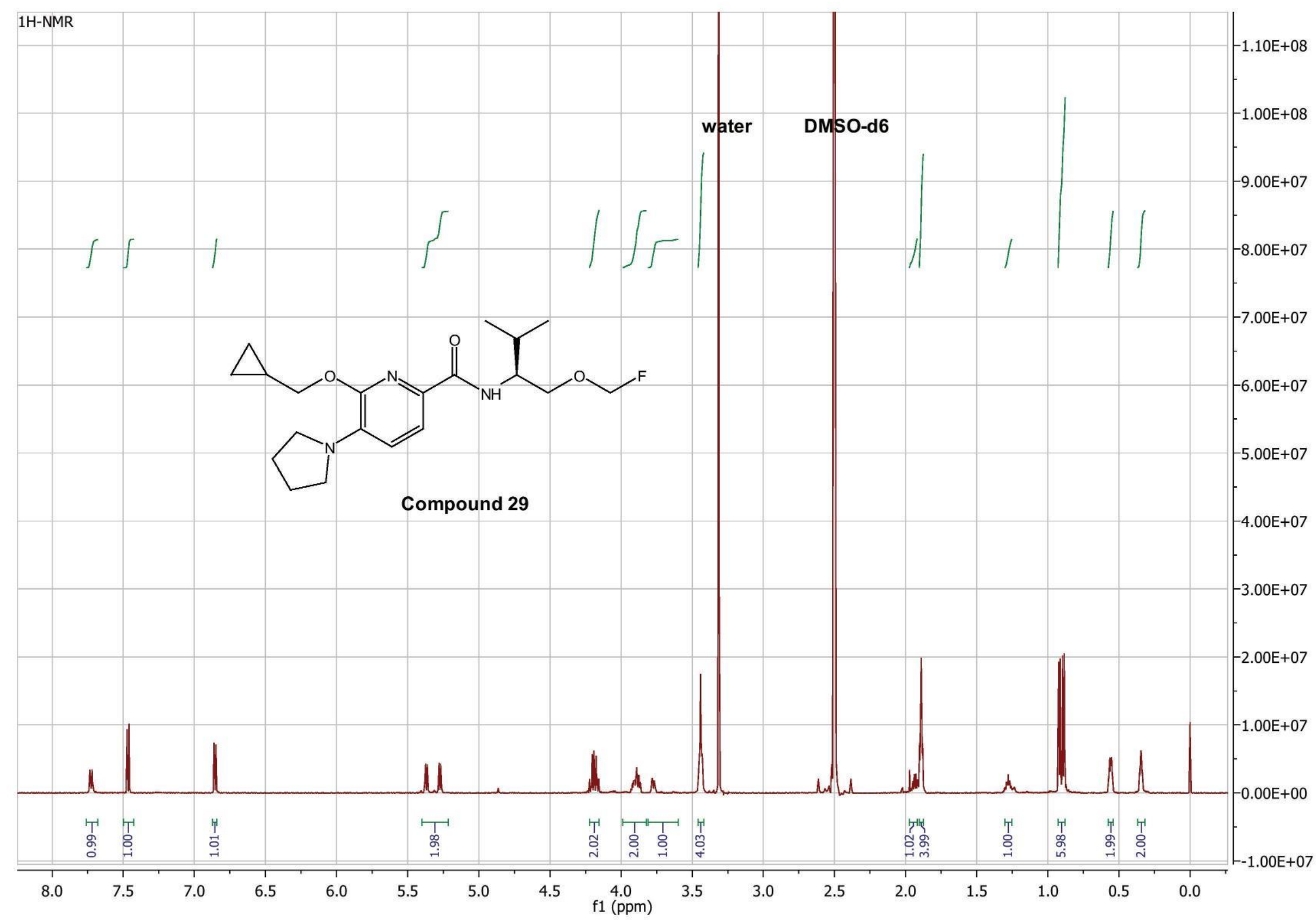




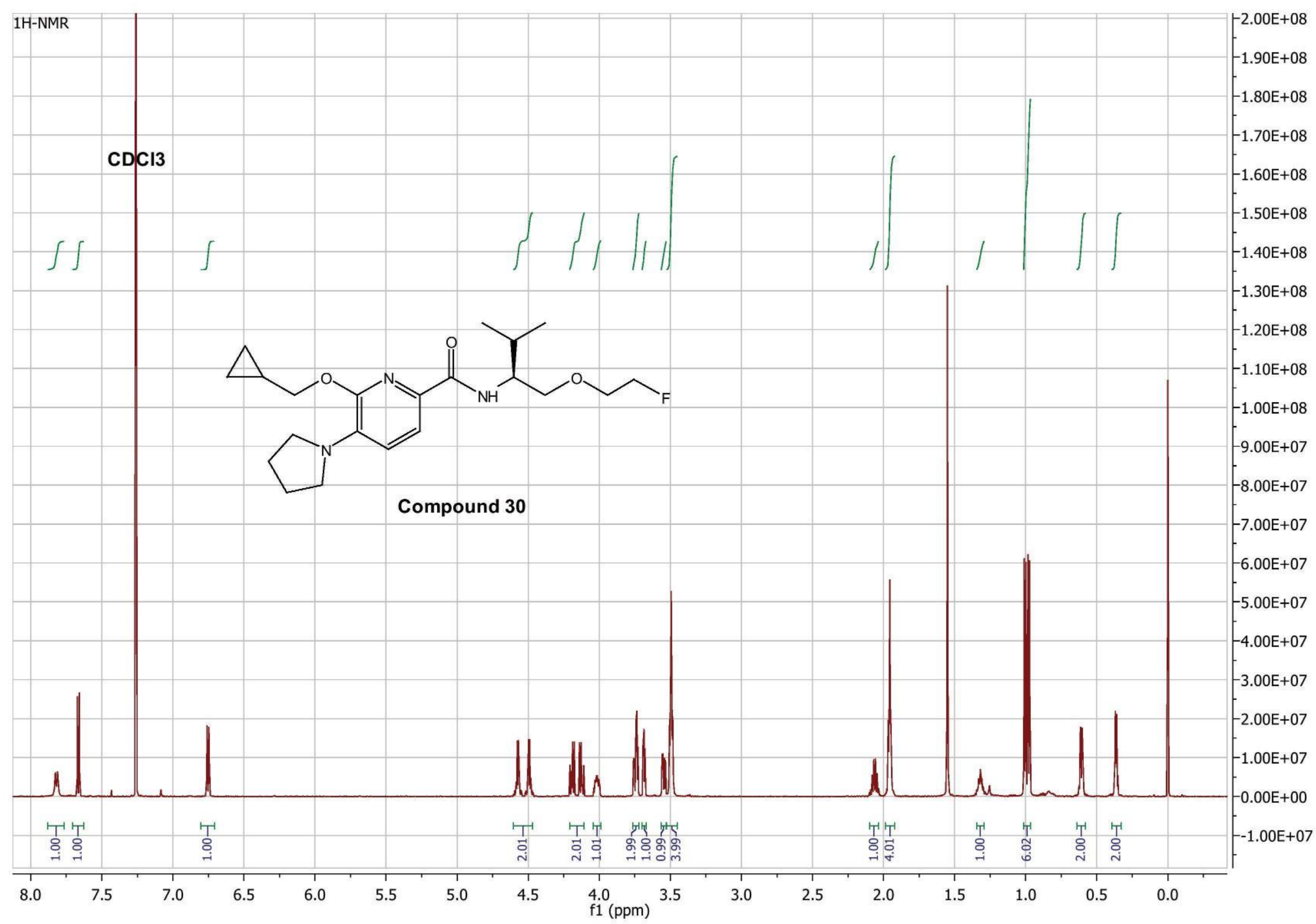




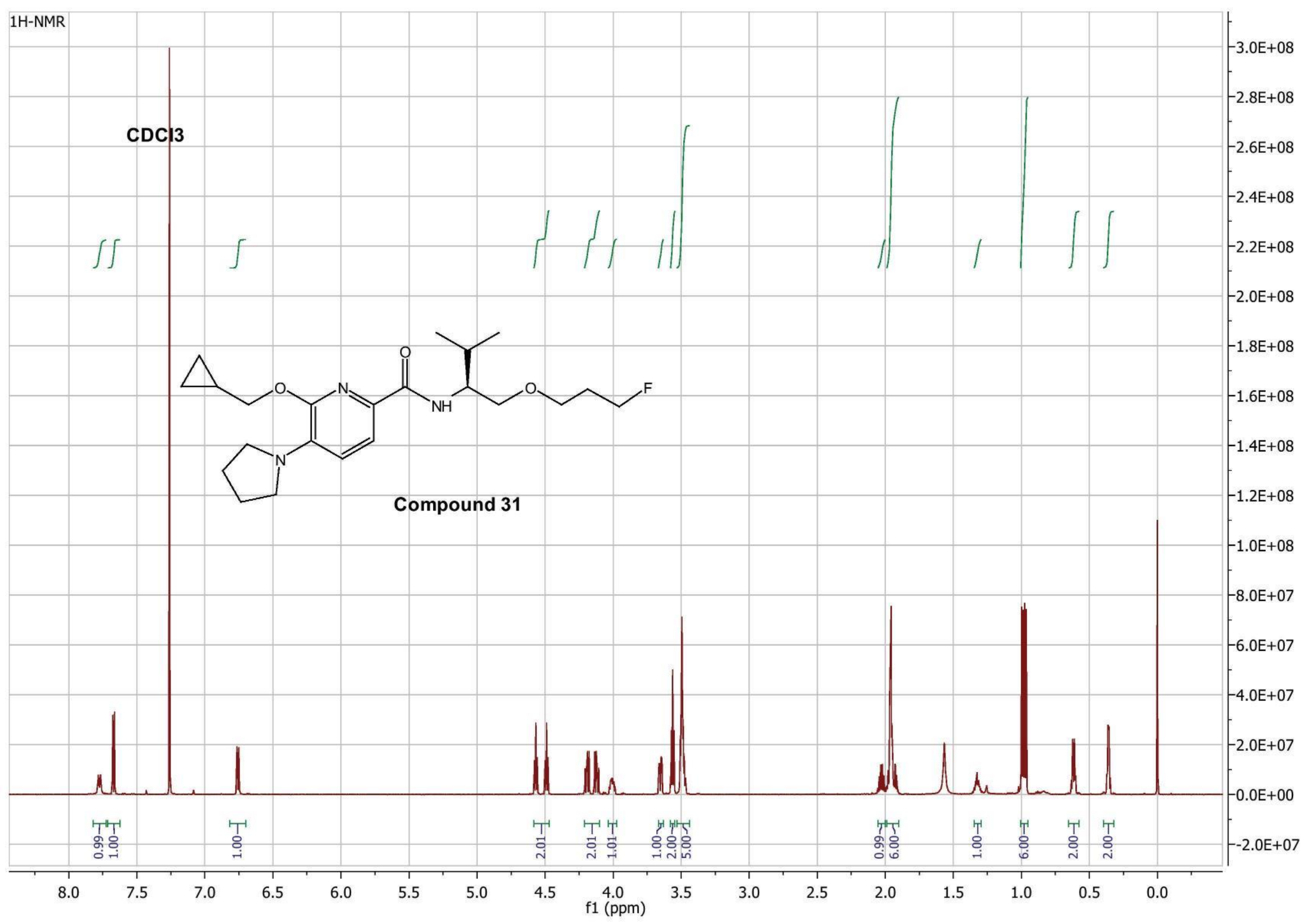




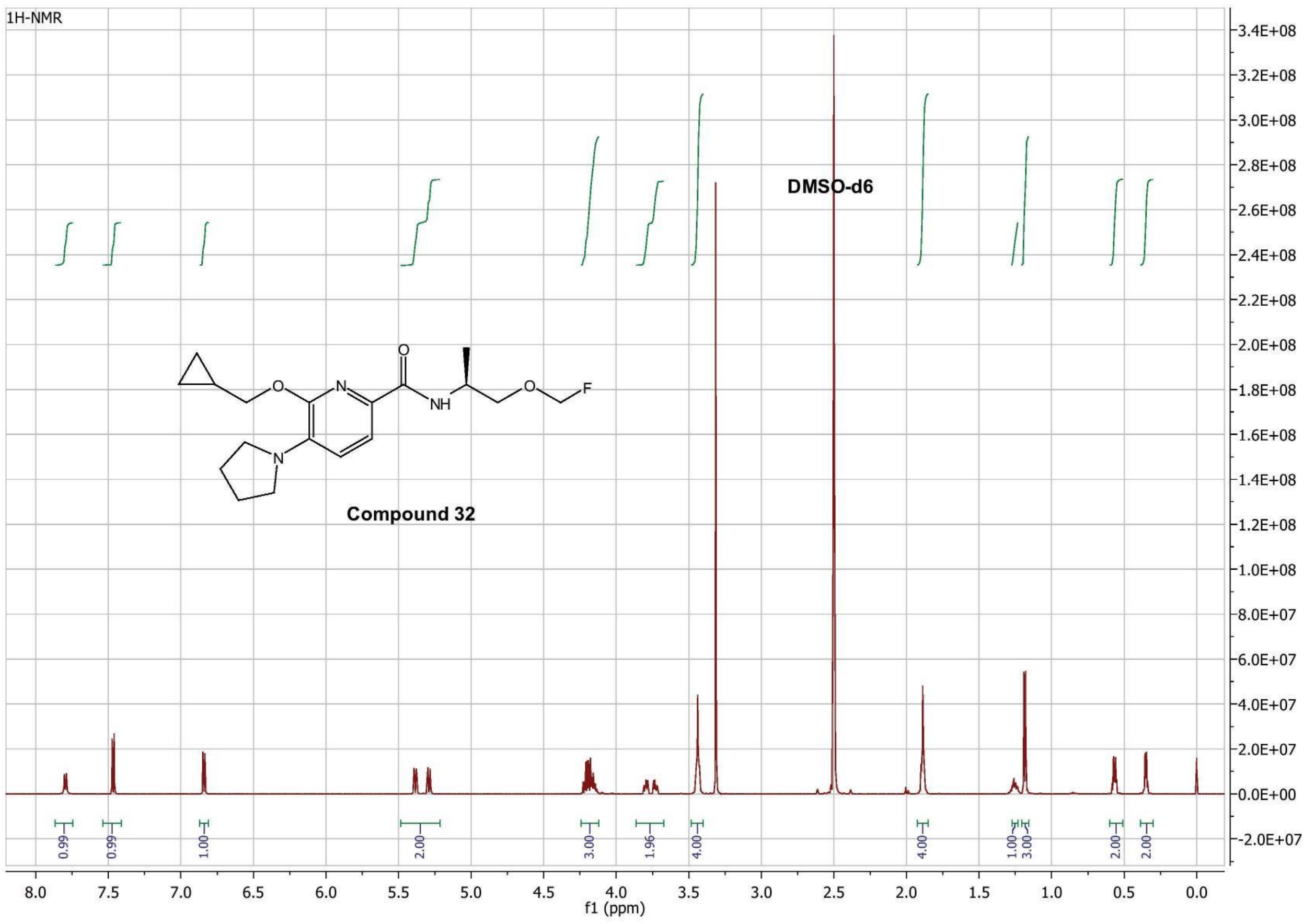




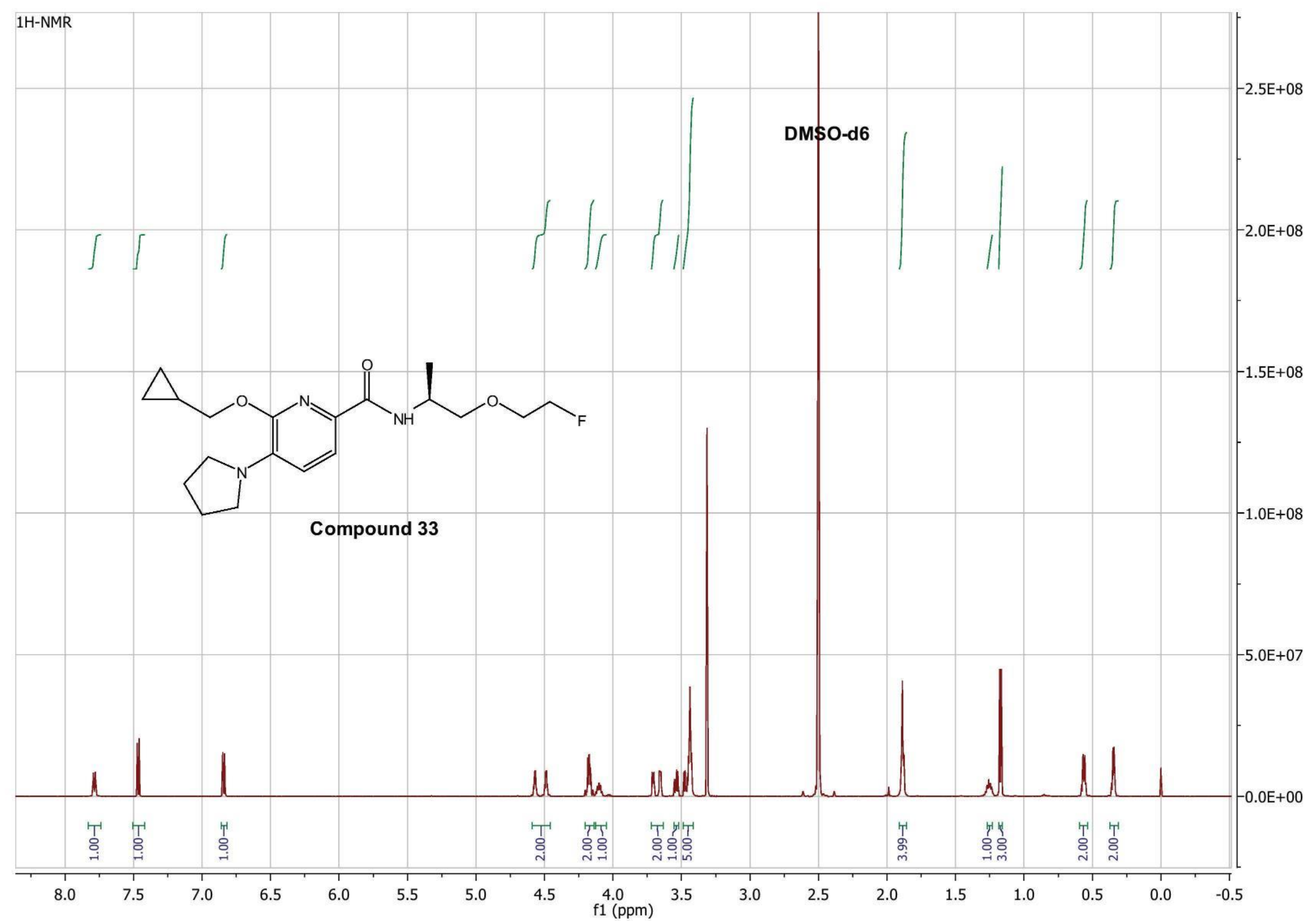




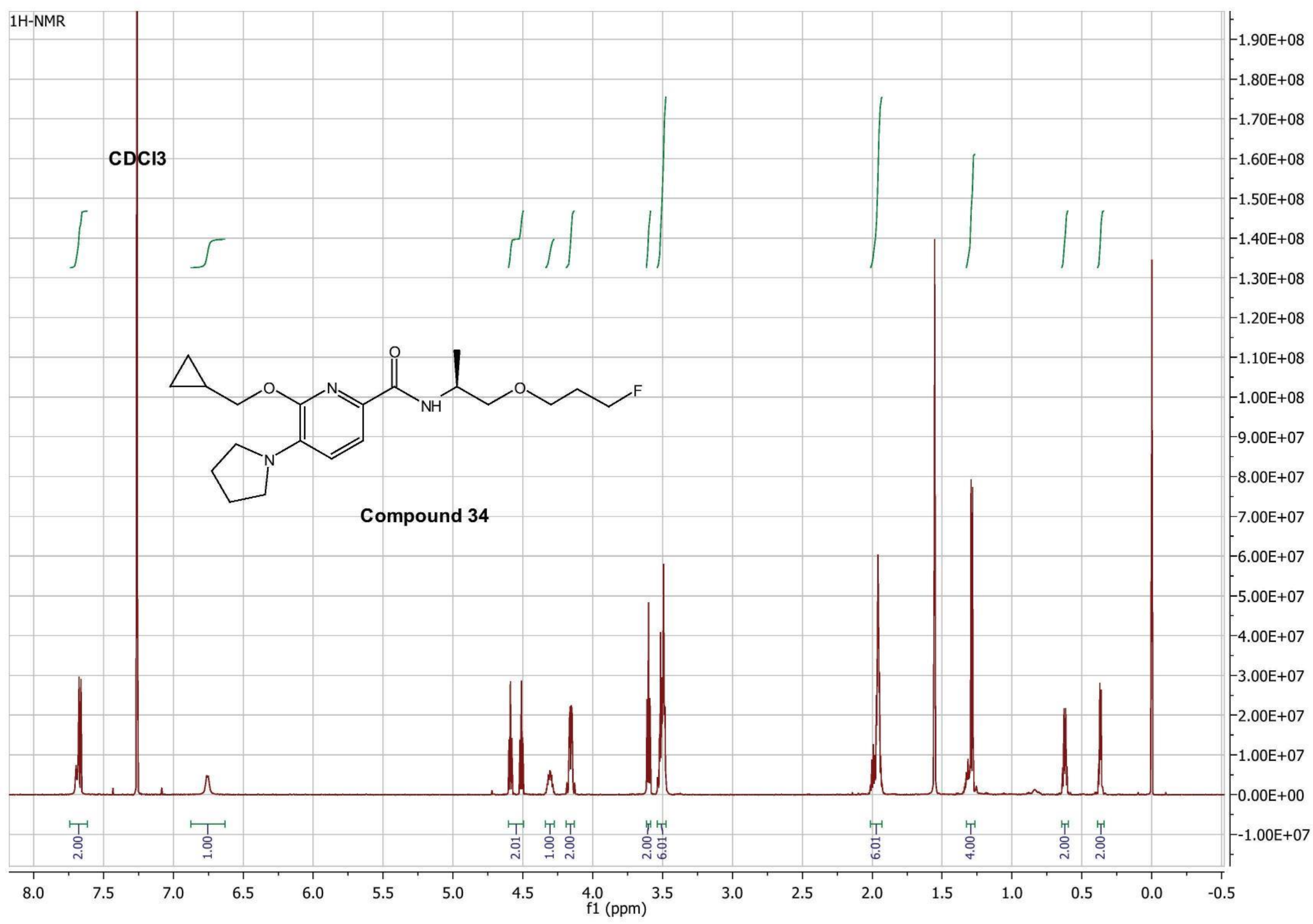




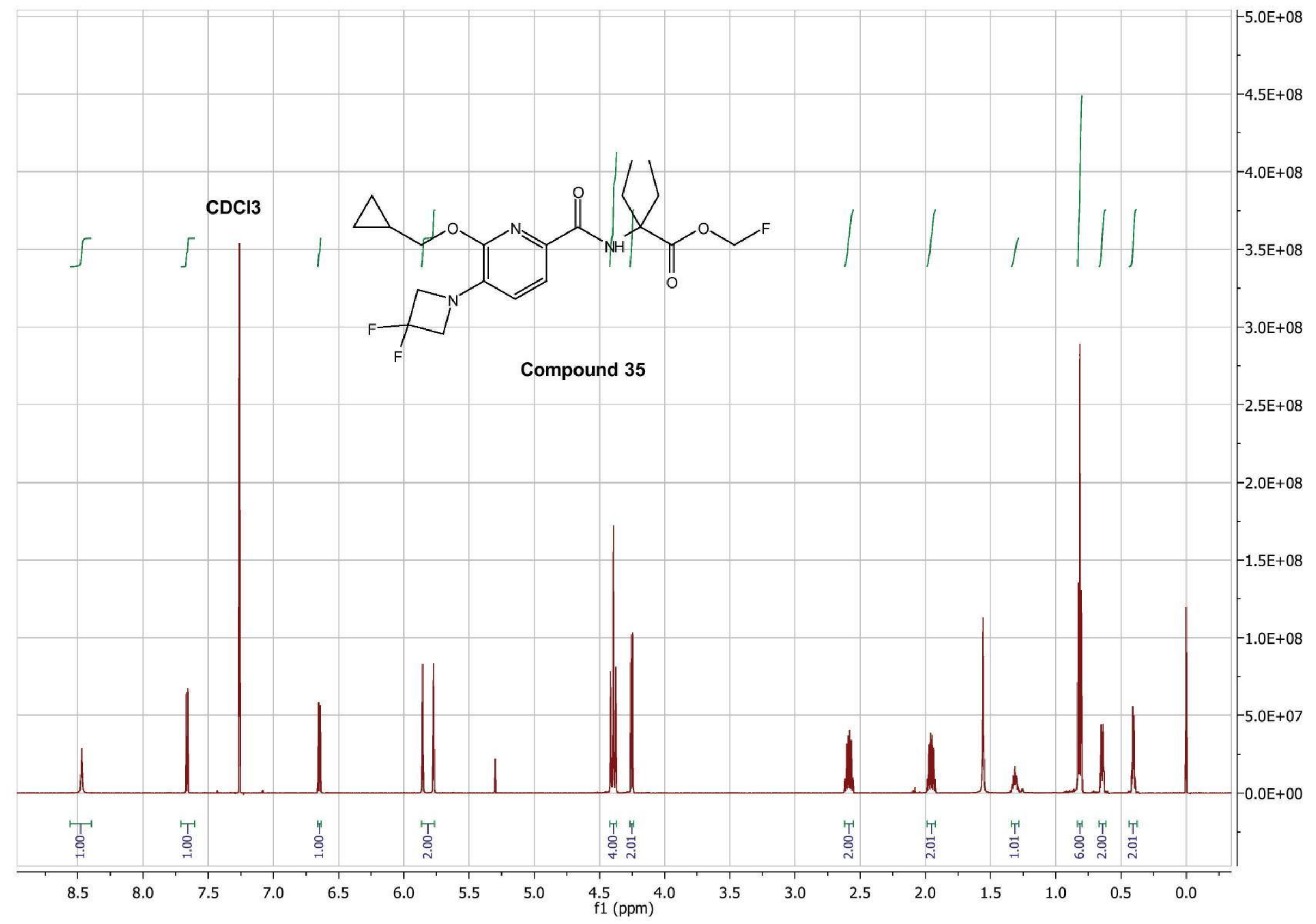









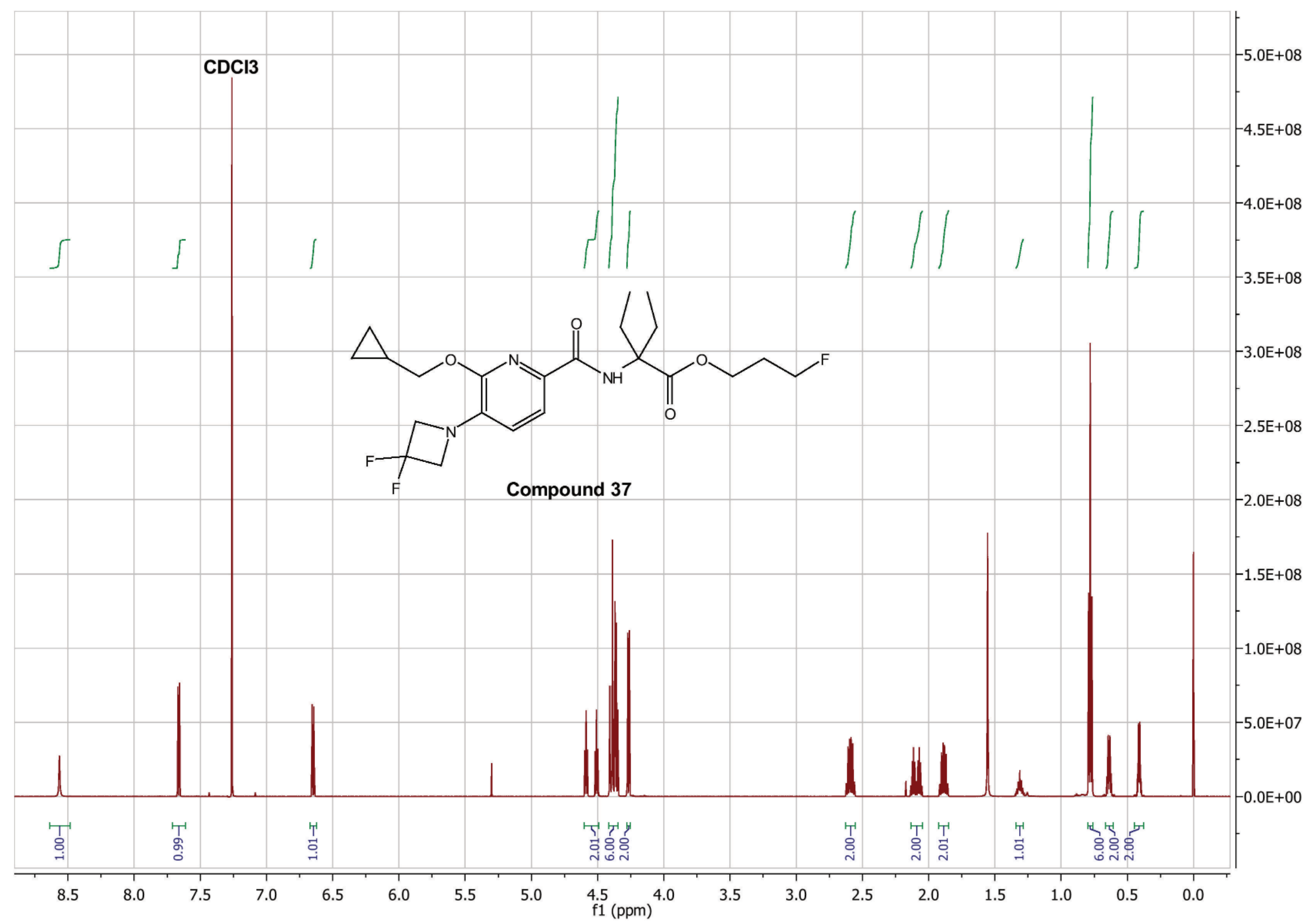




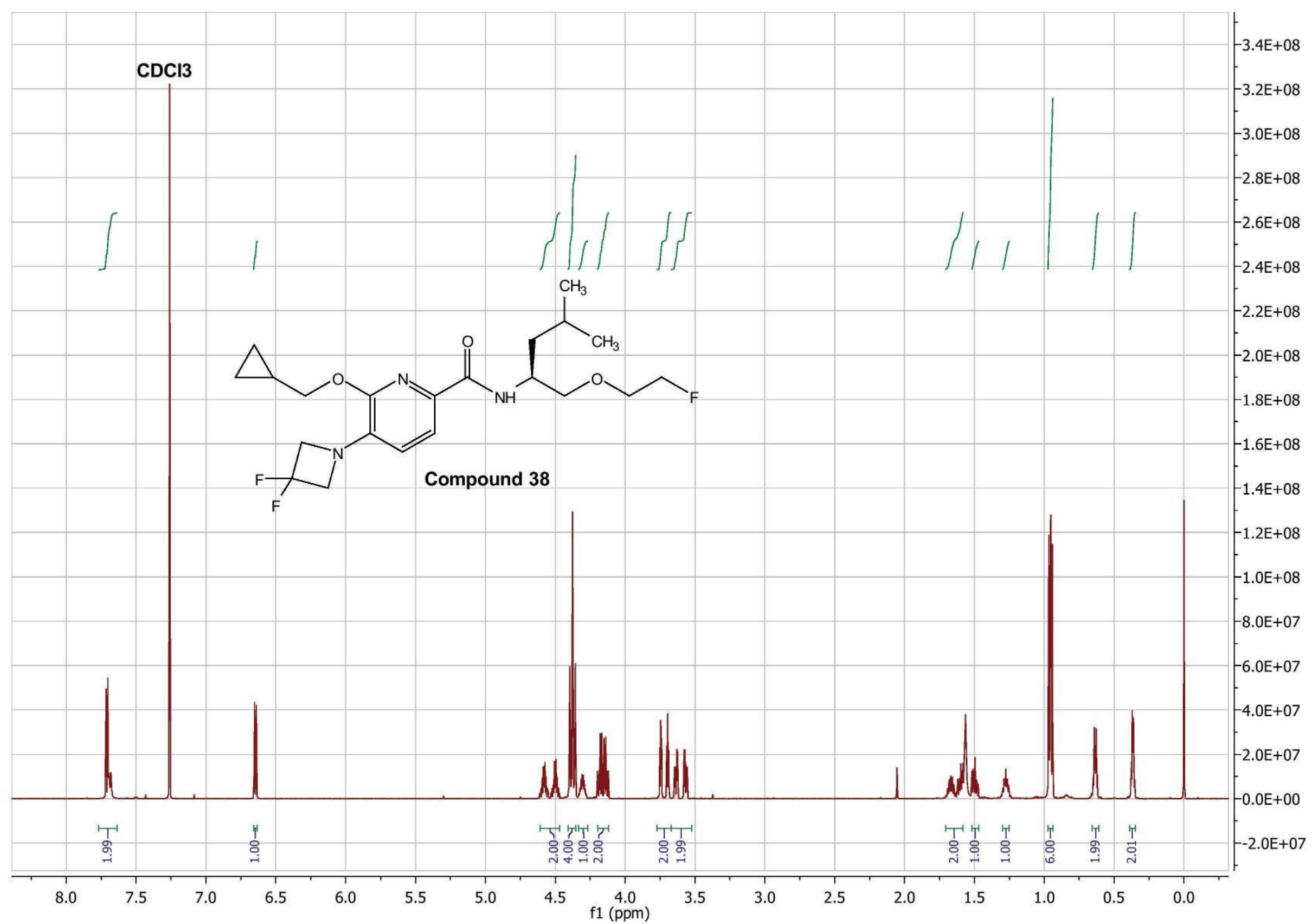

